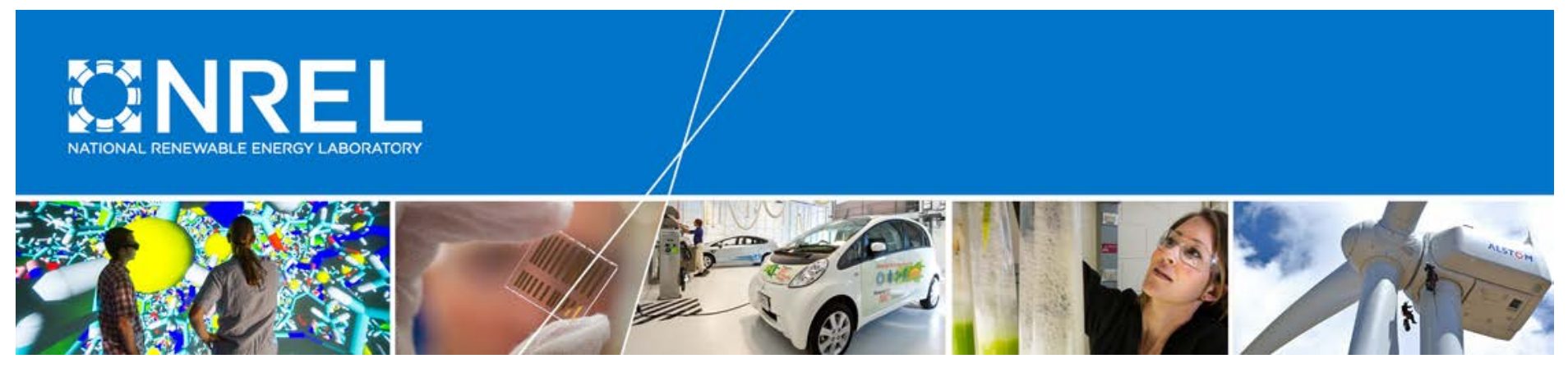

\title{
Investigating Power System Primary and Secondary Reserve Interaction under High Wind Power Penetration
}

Yingchen Zhang, Jin Tan, Ibrahim Krad, Rui Yang, and Vahan Gevorgian National Renewable Energy Laboratory

Erik Ela

Electric Power Research Institute

NREL is a national laboratory of the U.S. Department of Energy Office of Energy Efficiency \& Renewable Energy Operated by the Alliance for Sustainable Energy, LLC

This report is available at no cost from the National Renewable Energy Laboratory (NREL) at www.nrel.gov/publications.

Technical Report

NREL/TP-5D00-64637

December 2016

Contract No. DE-AC36-08G028308 


\section{Investigating Power System Primary and Secondary Reserve Interaction under High Wind Power Penetration}

Yingchen Zhang, Jin Tan, Ibrahim Krad, Rui Yang, and Vahan Gevorgian National Renewable Energy Laboratory

Erik Ela

Electric Power Research Institute

Prepared under Task No. WE14.9C01
NREL is a national laboratory of the U.S. Department of Energy Office of Energy Efficiency \& Renewable Energy Operated by the Alliance for Sustainable Energy, LLC

This report is available at no cost from the National Renewable Energy Laboratory (NREL) at www.nrel.gov/publications.

\section{Technical Report}

NREL/TP-5D00-64637

December 2016

Contract No. DE-AC36-08G028308
National Renewable Energy Laboratory 15013 Denver West Parkway Golden, CO 80401

303-275-3000 • www.nrel.gov 


\section{NOTICE}

This report was prepared as an account of work sponsored by an agency of the United States government. Neither the United States government nor any agency thereof, nor any of their employees, makes any warranty, express or implied, or assumes any legal liability or responsibility for the accuracy, completeness, or usefulness of any information, apparatus, product, or process disclosed, or represents that its use would not infringe privately owned rights. Reference herein to any specific commercial product, process, or service by trade name, trademark, manufacturer, or otherwise does not necessarily constitute or imply its endorsement, recommendation, or favoring by the United States government or any agency thereof. The views and opinions of authors expressed herein do not necessarily state or reflect those of the United States government or any agency thereof.

This report is available at no cost from the National Renewable Energy Laboratory (NREL) at www.nrel.gov/publications.

Available electronically at SciTech Connect http:/www.osti.gov/scitech

Available for a processing fee to U.S. Department of Energy and its contractors, in paper, from:

U.S. Department of Energy

Office of Scientific and Technical Information

P.O. Box 62

Oak Ridge, TN 37831-0062

OSTI http://www.osti.gov

Phone: 865.576.8401

Fax: 865.576.5728

Email: reports@osti.gov

Available for sale to the public, in paper, from:

U.S. Department of Commerce

National Technical Information Service

5301 Shawnee Road

Alexandra, VA 22312

NTIS http://www.ntis.gov

Phone: 800.553 .6847 or 703.605 .6000

Fax: 703.605.6900

Email: orders@ntis.gov 


\section{List of Acronyms}

ACE

AGC

DFIG

FESTIV

KERMIT

MAFRIT

PFR

PSLF

$\mathrm{PSS} / \mathrm{E}$ area control error

automatic generation control

doubly-fed induction generator

Flexible Energy Scheduling Tool for Integrating

Variable Generation

Renewable Energy Modeling and Integration

Tool

Multi-Area Frequency Response Integration

Tool

primary frequency response

Positive Sequence Load Flow

Power System Simulator for Engineering 


\section{Executive Summary}

Power system frequency needs to be maintained close to its nominal value at all times to successfully balance load and generation and maintain system reliability. Adequate primary frequency response and secondary frequency response are the primary forces to correct an energy imbalance at the second-to-minute level. As wind energy becomes a larger portion of the world's energy portfolio, there is an increased need for wind to provide frequency response. This paper addresses one of the major concerns about using wind for frequency regulation: the unknown factor of the interaction between primary and secondary reserves. The lack of a commercially available tool to model this has limited the energy industry's understanding of when the depletion of primary reserves will impact the performance of secondary response or vice versa. This paper investigates the issue by developing a multi-area frequency response integration tool with combined primary and secondary capabilities. The simulation is conducted in close coordination with economical energy scheduling scenarios to ensure credible simulation results. 


\section{Table of Contents}

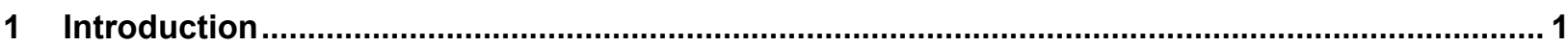

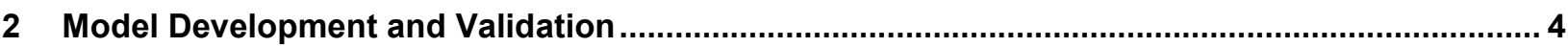

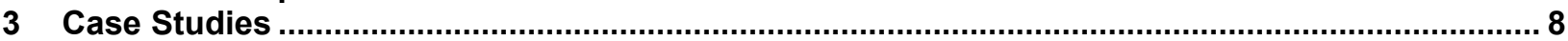

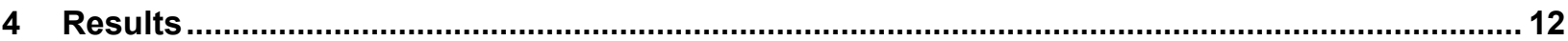

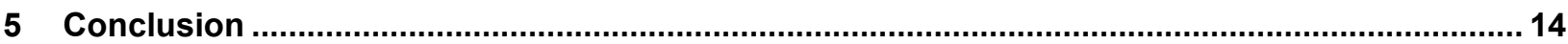

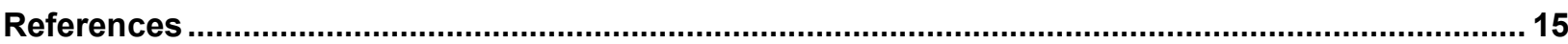

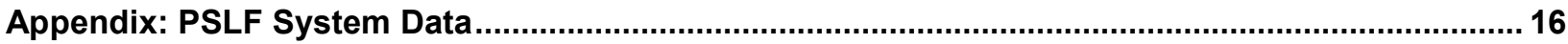




\section{List of Figures}

Figure 1. Overall architecture of the MAFRIT simulation platform........................................................ 3

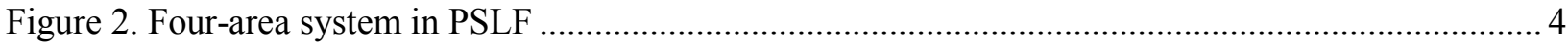

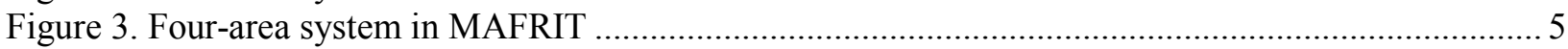

Figure 4. Comparison of rotor speed and active power of all generators in PSLF and Simulink................ 6

Figure 5. Comparison of terminal voltages (magnified on the right) of all generators in PSLF and

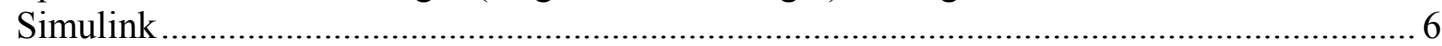

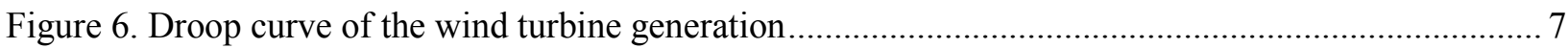

Figure 7. Wind output (MAFRIT) with and without AGC for the 1-hour simulation................................. 8

Figure 8. Scheduling (FESTIV) and real output (MAFRIT) of the wind turbine generators for 24 hours and the display of system load, frequency, and ACE ................................................. 9

Figure 9. Scheduling (FESTIV) and real output (MAFRIT) of the wind turbine generators for 24 hours and the display of system load, frequency, and ACE under 18\% wind energy

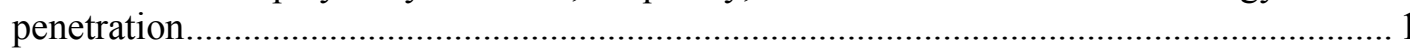

Figure 10. Scheduling (FESTIV) and real output (MAFRIT) of the wind turbine generators for 1 hour showing the system load, frequency, and ACE under $18 \%$ wind energy penetration............ 10

Figure 11. Wind power and system frequency when load increases by $50 \mathrm{MW}$ at $\mathrm{t}=2,504 \mathrm{~s} \ldots \ldots \ldots \ldots \ldots . .12$

Figure 12. Wind power and system frequency when load increases by $50 \mathrm{MW}$ at $\mathrm{t}=1,900 \mathrm{~s} \ldots \ldots \ldots \ldots \ldots . . .13$

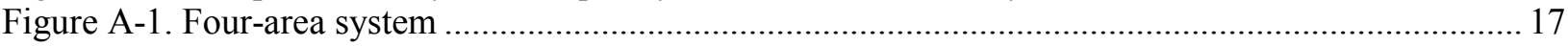

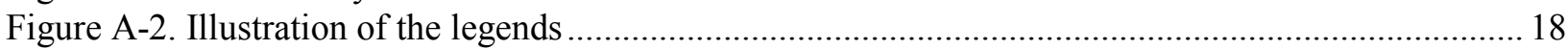

\section{List of Tables}

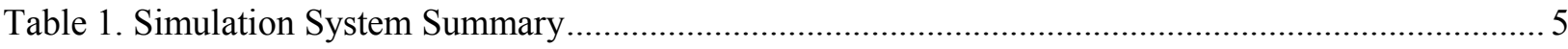

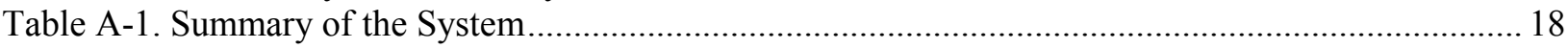

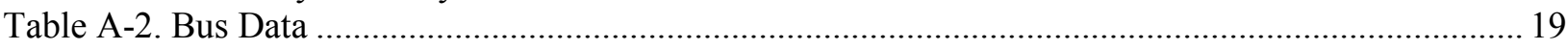

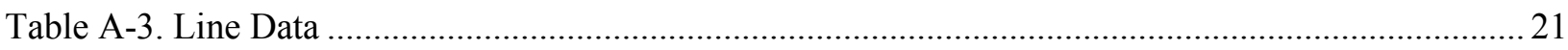

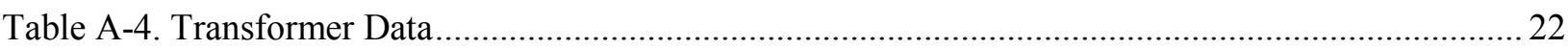

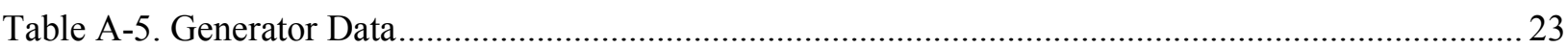

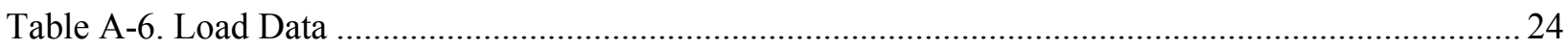

Table A-7. Synchronous Generator Model and Parameter ...................................................................... 25

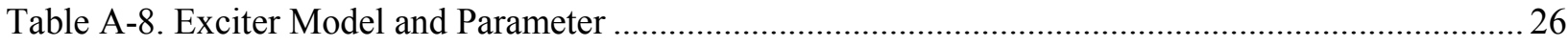

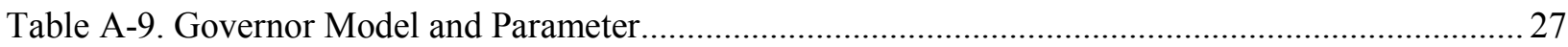

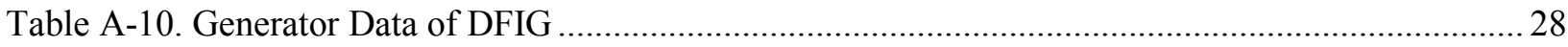

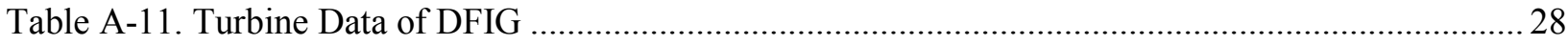

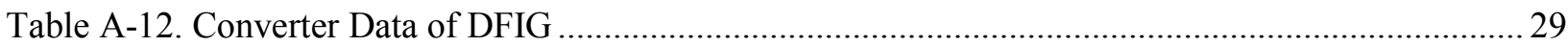

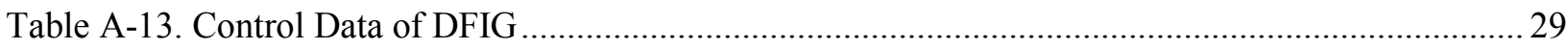

Table A-14. Parameter of Simplified Wind Power Plant Model ............................................................... 30 


\section{Introduction}

To successfully manage the nation's bulk electric power system, the balance of generation must be maintained at all timescales. The timescale at which this occurs will dictate the operation needed to ensure that the system is in balance. An imbalance between generation and load can overload transmission lines and cause unscheduled power flows, voltage magnitude fluctuations, and electrical frequency deviations. A severe frequency deviation can lead to a partial system failure or worse, a cascading failure (e.g., blackout). Electric power system operators use a variety of scheduling and control techniques to maintain the electricity frequency close to its nominal value at all times. An interconnected power system must have adequate resources to respond to a variety of contingency events to ensure rapid restoration of the frequency. Primary frequency response (PFR) - also called primary control reserve [1] and frequency responsive reserve [2] - is the capacity available for automatic local response to frequency excursions through turbine speed that adjusts to counter-frequency deviations to stabilize the frequency [3]. PFR occurs shortly after an event and acts to stabilize the frequency deviation to a steady-state level. Although primary control is a function of local controllers responding to a frequency deviation, secondary freqeuency response control is a centralized control directed by the system operator. It utilizes automatic generation control (AGC) to restore the system frequency to its nominal value and keep the interchanges between balancing authority areas to their scheduled levels.

Wind power has the capability to provide both forms of responses through active power control. To provide upward reponse to correct under-frequency conditions, wind power plants track their maximum available power and schedule their output below the maximum power point [4]. This is different from conventional generators, which can increase or decrease their fuel flow to control their power output willingly. With increased wind power penetration in all major North American interconnections, there is an increased need to expand the use of frequency control capabilities that can be provided by wind energy technology [5]. If designed correctly, active power control from wind power can perform better than conventional generators in terms of speed and accuracy because most existing wind power plants interface with power grids through power electronics devices [6].

One of the challenges of using wind power for frequency regulation is the unknown outcome when primary and secondary reserves interact [5]. In current system operations, PFR reserve is not scheduled in unit commitment and real-time dispatch because it is assumed that it is an inherent function of conventional generators (via direct control of fuel flows through steam valve, gate valve, or combustor) and that there is always ample supply. However, with increased penetrations of wind, this may not always be the case. Under current operating mechanisms, if wind power is enabled to provide both primary and secondary responses but only secondary reserve is scheduled through the ancillary services market, if an event happens that deployes PFR reserves there will be a deficiency on the energy that restores the system frequency response to its nominal value. Also, under circumstances in which the secondary reserve is under-procured, primary response will automatically act to further restore frequency. As a result, the remaining primary response may not be available to stabilize the frequency after a sudden loss of generation.

Mitigating these challenges requires a tool that can realistically model the interactions between primary and secondary control. There are tools that are designed to implement AGC in an extended system simulation. For example, the Power System Simulator for Engineering (PSS/E) is a software tool that simulates power system steady-state and dynamic performance. In 2011, PSS/E rolled out a new function called "extended term dynamic 
simulation," which extended the time frame for dynamic simulations to virtually unlimited and implemented slow-moving controls, such as AGC, switched shunts, and transformer tap changing [7][8]. PSS/E uses implicit integration to solve differential equations with changing time steps. This function offers the means to change simulation time steps by choosing different modes; however, when the user choses large time steps, the fast responses will be filtered. The unit allocation is calculated using unit base point, unit maximum regulation, and the ramp rate.

KEMA, Inc., published the Renewable Energy Modeling and Integration Tool (KERMIT) [9] to simulate power system frequency behavior during a 24-hour time interval. The tool incorporates an AGC model that responds to non-fault events, such as a generator trip, load shedding, and variation of renewable resources. KERMIT is designed to simulate a power system's dynamic resources and provides simulations from 1 second to 25 hours. This tool incorporates production models, such as balancing market clearing, scheduling ramp lookahead, generation scheduling, and load/renewable resource forecasting; and system dynamic models, such as inertias, turbine governors, excitations, and AGC. However, the major drawback is that KERMIT does not include a detailed network model; it represents the control areas as nodes in a reduced network. The inter-area flows are calculated by relative phase angles between areas. (The phase angles are decided by the area frequency and instantaneous mismatch of the area's mechanical-electrical power.) As a result, KERMIT does not have individual dynamic responses for each generator, and the entire network is lossless. KERMIT was utilized to study the impact of renewable generation on the California grid [10] [11]. This study primarily looked into the variability associated with renewable resources and how energy storage provides AGC and can help mitigate variability; thus, the study focused on secondary reserves and the system response. A similar study was done on the PJM grid to assess the effectiveness of AGC in a frequency regulation market [12]. All of the KERMIT-related studies focused on secondary reserves and AGC control without a balanced focus on PFR.

The Flexible Energy Scheduling Tool for Integrating Variable Generation (FESTIV) tool developed by researchers at the National Renewable Energy Laboratory has focused on impacts of area control error (ACE) and frequency with a detailed inclusion of electricity market operation (including security-constrained unit commitment and economic dispatch) [14]. It is a forward-looking, electricity scheduling simulation software, and it includes security-constrained unit commitment, security-constrained economic dispatch, and AGC sub-models. Each sub-model's output serves as the input to subsequent sub-models. However, it does not model the dynamic behavior of PFR or the impacts of multi-area interconnections.

In this study, we address this challenge by designing a Multi-Area Frequency Response Integration Tool (MAFRIT) in Simulink to simulate the frequency dynmaic of the grid and using FESTIV to provide economical scheduling. In MAFRIT, we model a power system that has multiple balancing authority areas, and we calculate the ACE based on the frequency deviation of each area and the tie-line flow deviation from the schedule. We decide the AGC participation factors based on an economic reallocation from the FESTIV scheduling. All of the generator set points in MAFRIT are updated every 5 minutes according to the energy scheduling. Within each 5 minutes, they adjust their output automatically based on the AGC signal to balance the load in a 4-second resolution. The overall architecture of the simulation platform is displayed in Figure 1. 


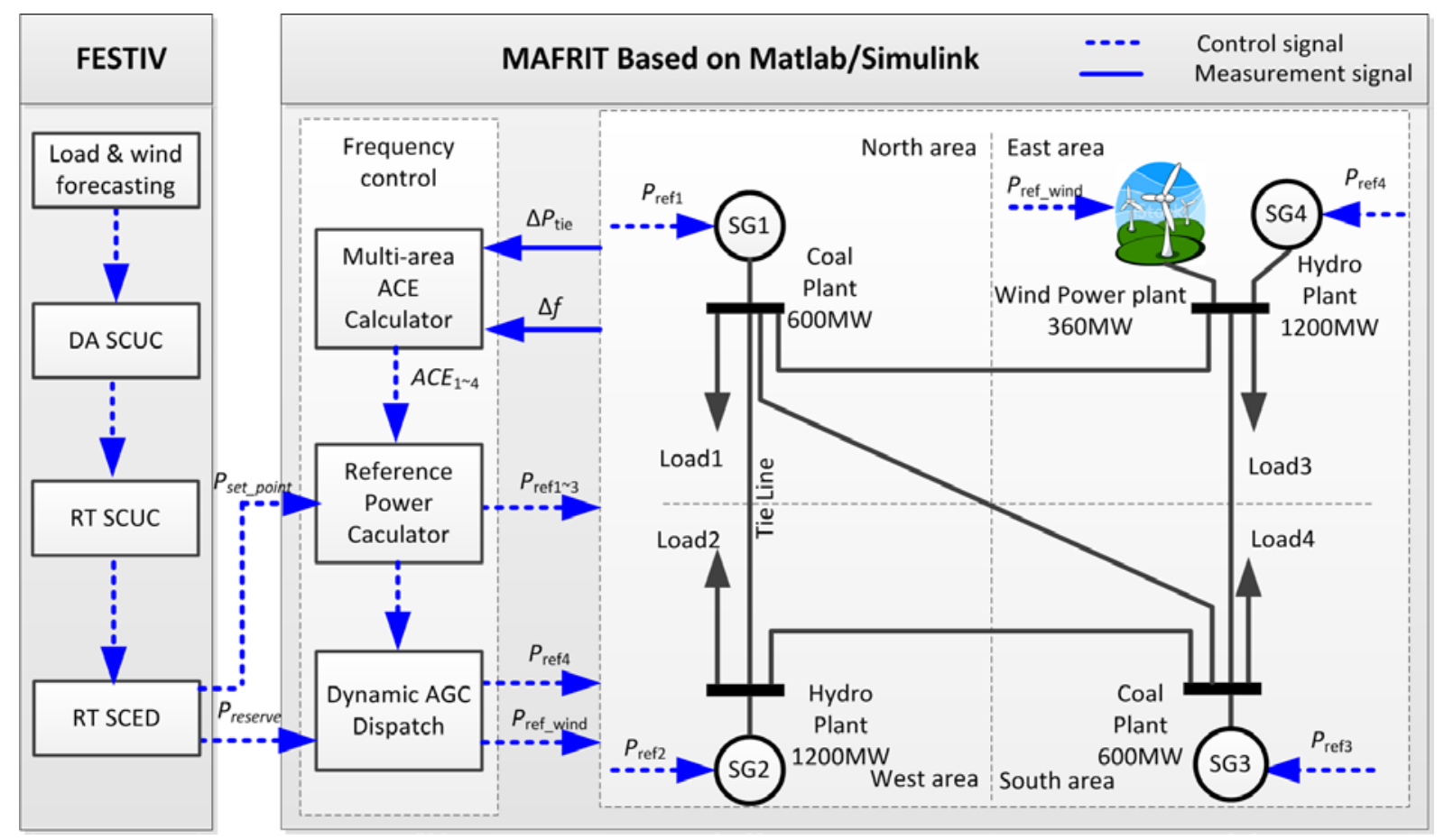

Figure 1. Overall architecture of the MAFRIT simulation platform

Section 2 describes the model development and validation. Section 3 and Section 4 provide case studies about the interactions between wind primary and secondary reserves. Section 5 provides a discussion and conclusion. 


\section{Model Development and Validation}

MAFRIT integrates PFR (primary freqeuncy response) with secondary frequency response (AGC). It simulates the power system dynamic response in a full-time spectrum with variable time steps, from milliseconds to minutes and hours to days. It is capable of simulating both normal and event conditions, and it can represent real power system operations and thus evaluate the adequacy of primary and secondary reserves. This unique interaction between a turbine governor model and a novel AGC model places special emphasis on electric power systems that have high penetrations of wind generation. To ensure the credibility of the model, a demonstration model provided by GE's Positive Sequence Load Flow (PSLF) dynamic simulation software is used and translated into the Simulink platform. The PSLF system layout is displayed in Figure 2, and the system layout modeled in MAFRIT is shown in Figure 3.

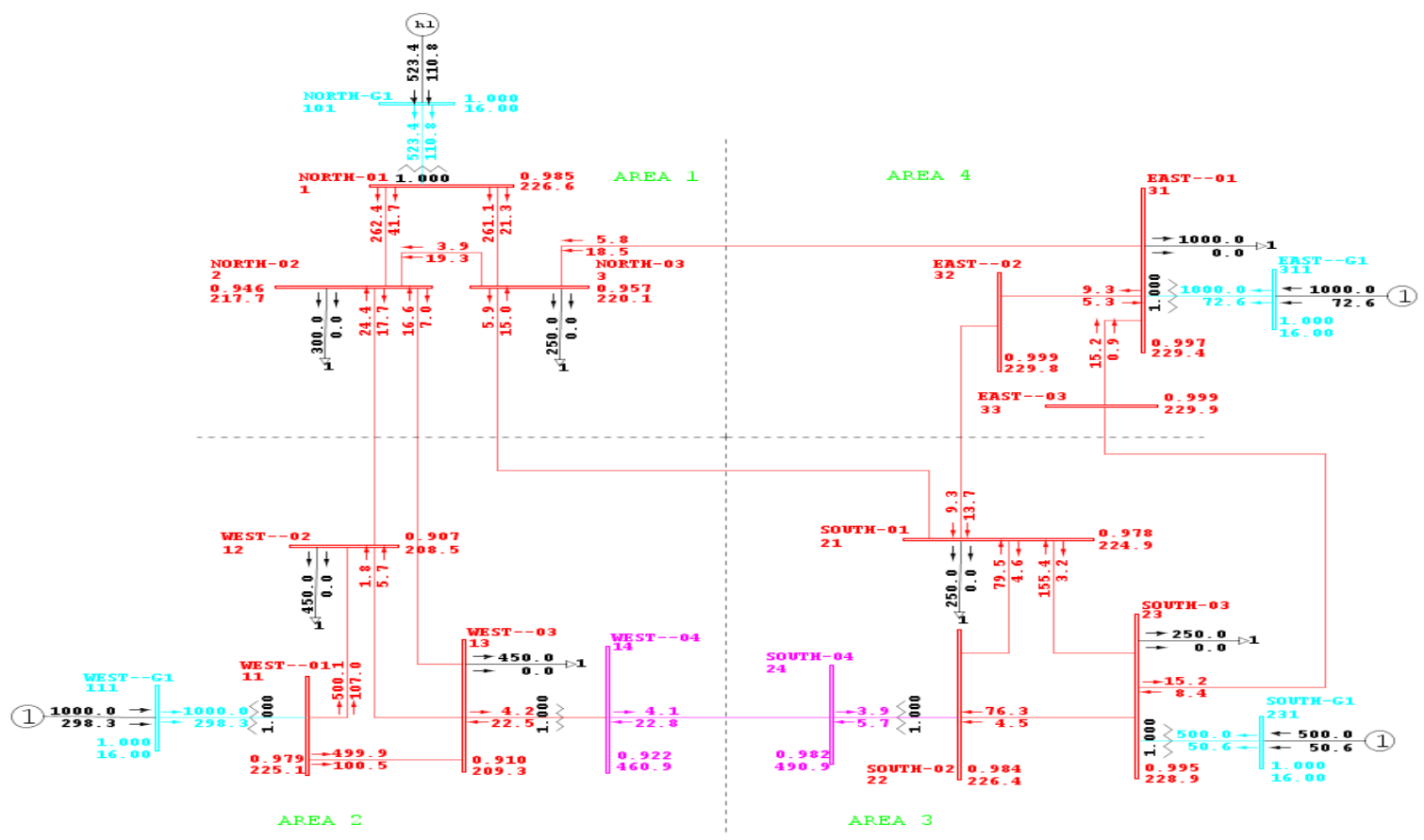

Figure 2. Four-area system in PSLF 


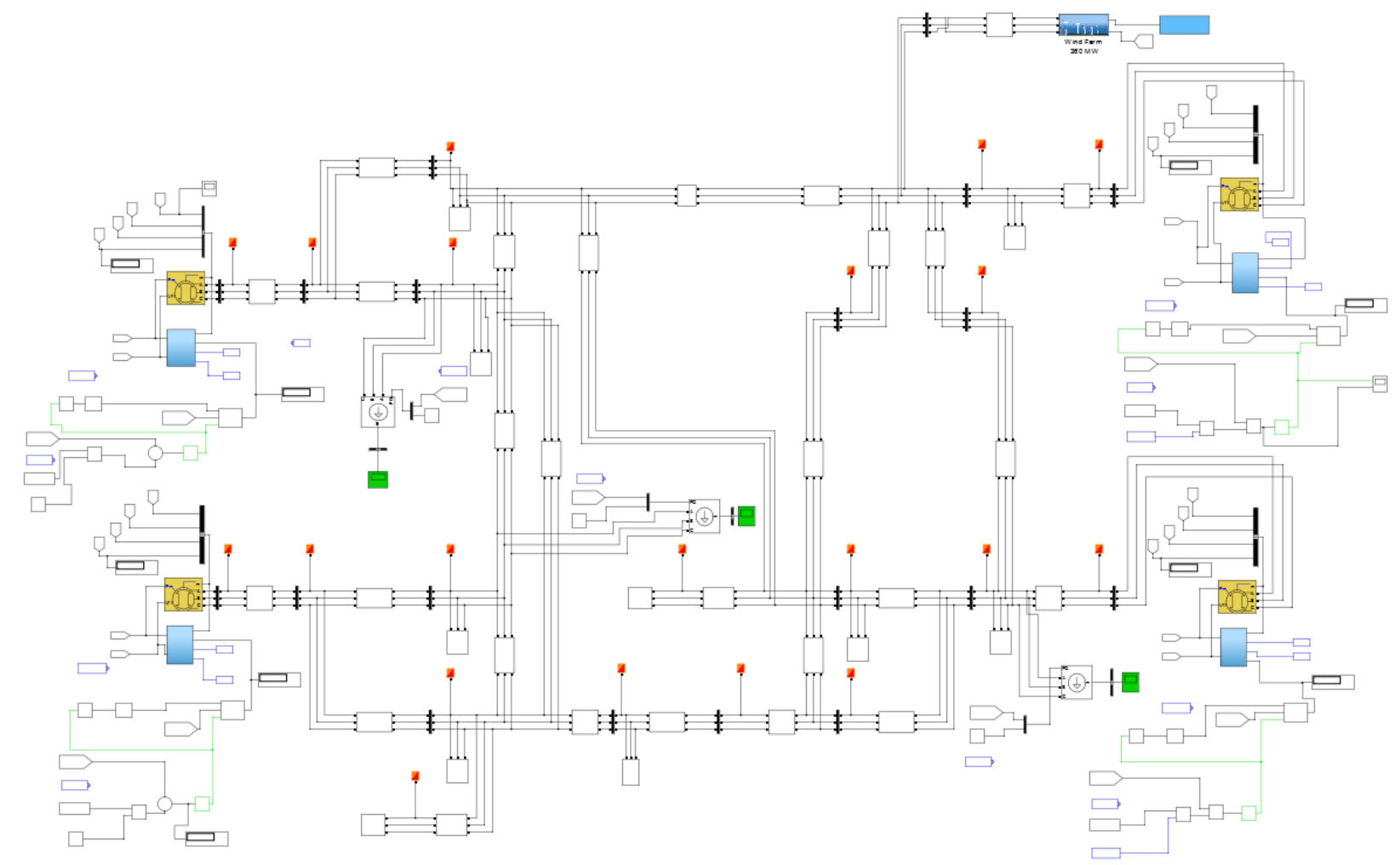

Figure 3. Four-area system in MAFRIT

A summary of the PSLF system is displayed in Table 1. Details about the system parameters - including buses, lines, transformers, generators, and loads — are included in the appendix.

Table 1. Simulation System Summary

\begin{tabular}{c|c}
\hline \hline & Number \\
\hline \hline Areas & 4 \\
\hline Buses & 18 \\
\hline Lines & 18 \\
\hline Transformers & 6 \\
\hline Generators & 4 \\
\hline Loads & 7 \\
\hline
\end{tabular}

The dynamic model of MAFRIT has been validated against the PSLF simulation, and the results are displayed in Figure 4 and Figure 5. Figure 4 shows the rotor speed and real power output of all the generators after a sudden increase in load. Figure 5 shows the terminal voltage magnitude of all of the generators after a fault. The performance of the Simulink model closely matches the results of the PSLF simulation. 

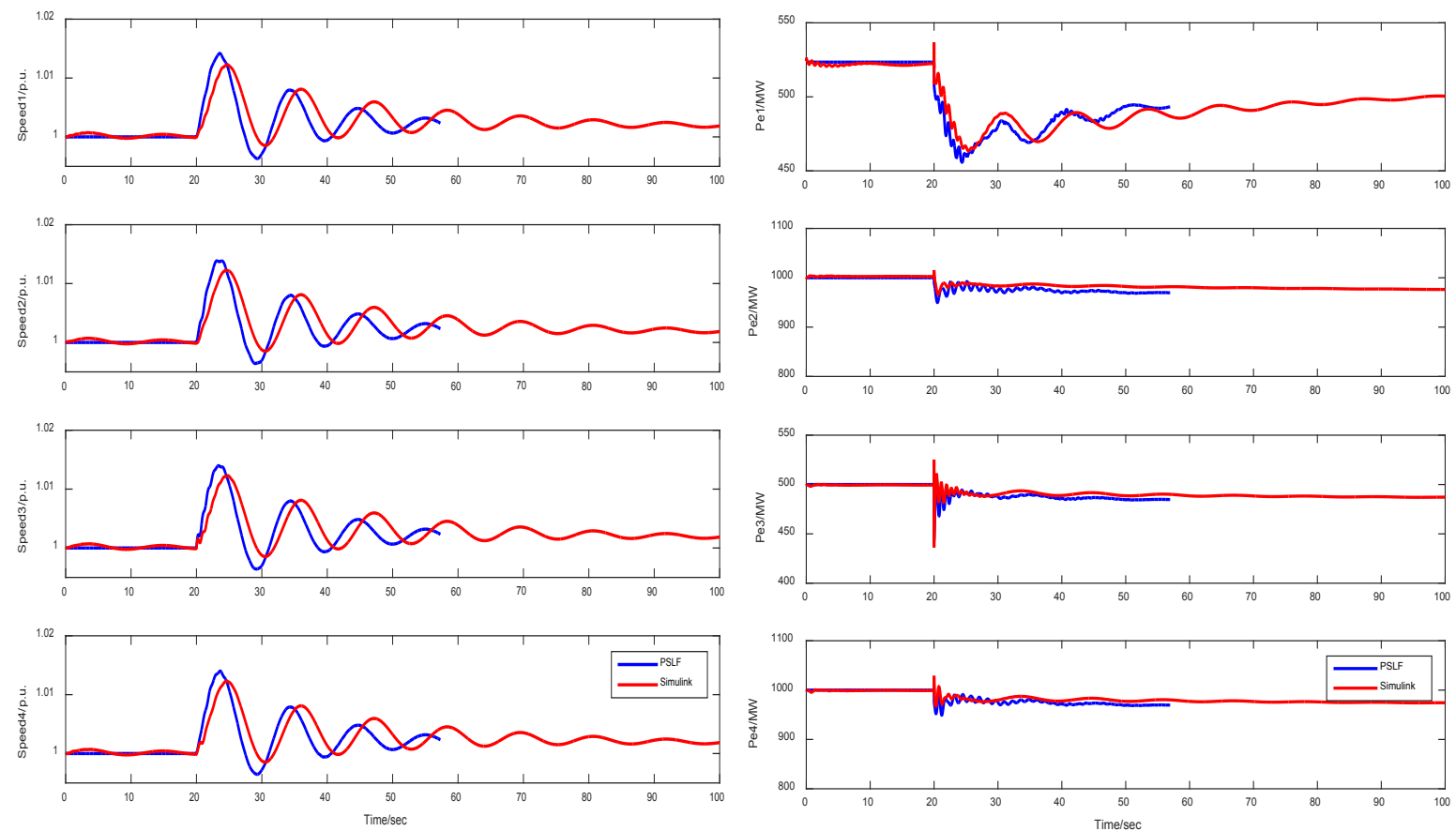

Figure 4. Comparison of rotor speed and active power of all generators in PSLF and Simulink
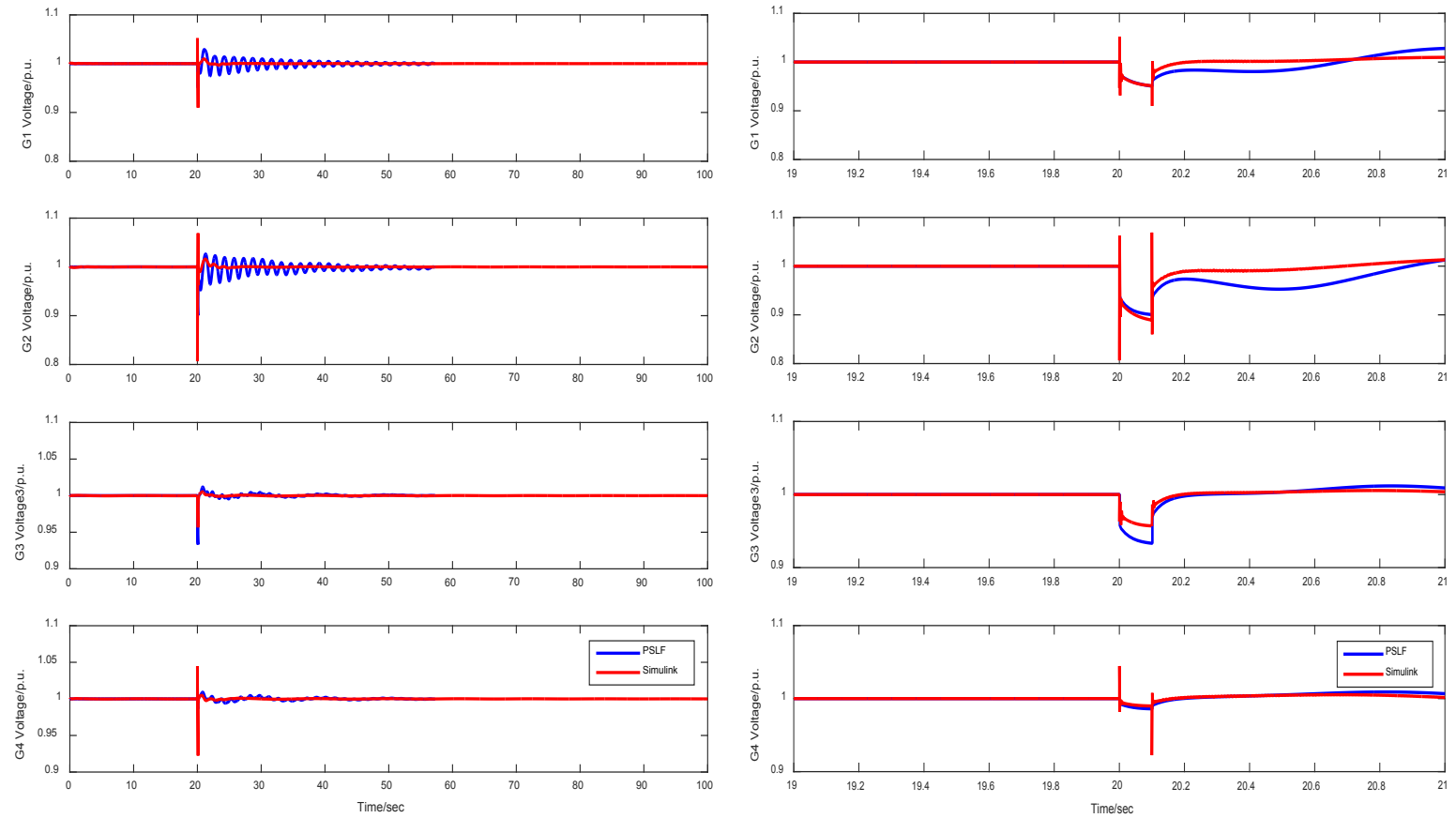

Figure 5. Comparison of terminal voltages (magnified on the right) of all generators in PSLF and Simulink

In addition to the validated dynamic model, an AGC controller is modeled in Simulink. The ACE calculation of the AGC controller is described below.

$A C E_{i}=\Delta P_{t i e, i}+\beta_{i} \Delta f_{i}, \quad \Delta P_{t i e, i}=\sum_{\substack{j=1 \\ j \neq i}}^{N} \Delta P_{t i e, i j}=\frac{2 \pi}{s}\left[\sum_{\substack{j=1 \\ j \neq i}}^{N} T_{i j} \Delta f_{i}-\sum_{\substack{j=1 \\ j \neq i}}^{N} T_{i j} \Delta f_{j}\right]$ 
where

- $\beta_{\mathrm{i}}$ is a bias factor of area $\mathrm{i}$

- $\Delta P_{t i e, i}$ is the tie-line power change of area $\mathrm{i}$

- $\Delta f_{i}$ is the frequency deviation of area $\mathrm{i}$

- $T_{i j}$ is the synchronizing torque coefficient between areas $\mathrm{i}$ and $\mathrm{j}$.

In addtion, a 360-MW doubly-fed induction generator (DFIG) based wind power plant [13] is added in Area 4. The PFR of the DFIG is implemented according to the droop curve shown in Figure 6. Under normal operating conditions with near-nominal system frequency the control is set to provide a specified margin by generating less power than is available from the unit. The reserve available (or "headroom") is the available energy curtailed shown as the reserve between the operational point and $\mathrm{P} 0$.

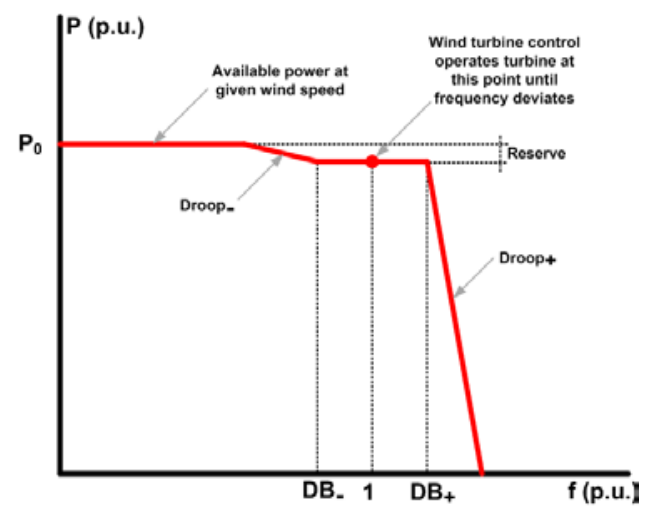

Figure 6. Droop curve of the wind turbine generation 


\section{Case Studies}

The purpose of this study is to investigate the adequacy of the primary and secondary reserves using MAFRIT. The credibility of the accuracy of the MAFRIT simulation lies in the dynamic model benchmarking using PSLF, as discussed above. It also lies in the natural connection to the energy scheduling tool FESTIV. It includes security-constrained unit commitment, security-constrained economic dispatch, and AGC sub-models. Each submodel's output serves as the input to subsequent sub-models [14]. The tool co-optimizes the energy and reserves to closely reflect the way in which system operators schedule energy in reality. This tool is completely configurable so that the effects of different operating strategies can be explored. This study uses FESTIV to generate schedules for all generators in MAFRIT. All generators are enabled to schedule regulating reserve. The scheduling assumes perfect forecasting errors for wind power. To ensure that wind power will be scheduled for reserve, its reserve cost is made lower than the other generators.

A close look at the 1-hour simulation results for the wind turbine generator's response when providing or not providing AGC is shown in Figure 7. When the wind turbine generator tracks only energy scheduling, it can change its output very rapidly. When a wind turbine generator helps restore system frequency, its output deviates from the energy schedule and there is a need to withold energy to provde up-ramping. In reality, ramp limiters are added to wind power plants, because their response can be very fast and increase frequency volatility. In this study, ramp limiters are not considered.

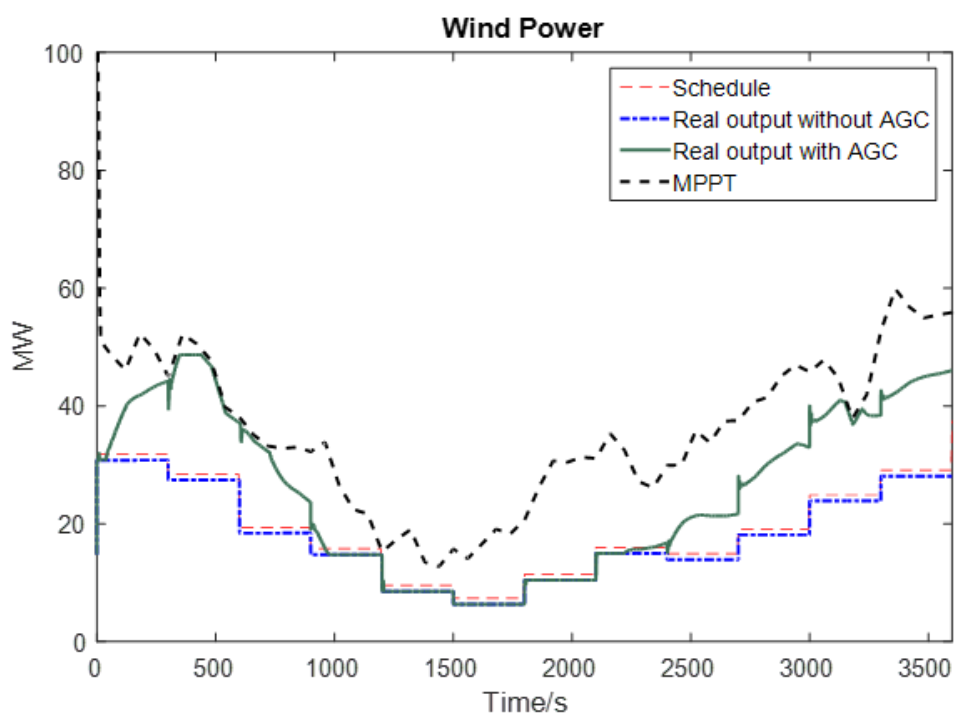

Figure 7. Wind output (MAFRIT) with and without AGC for the 1-hour simulation

The 24-hour simulation results are displayed in Figure 8. The load profile displayed is the aggregate of all loads at different parts of the system. The generators respond to load changes by following the 5-minute energy schedule and using 4-second AGC; therefore, their outputs deviate from the schedule. The wind turbine generator's output is also limited by its maximum power point tracking. This 24-hour simulation does not include any disturbances. The frequency deviations are caused by load ramping and the quick responses of the wind turbine to the dispatch signals. 

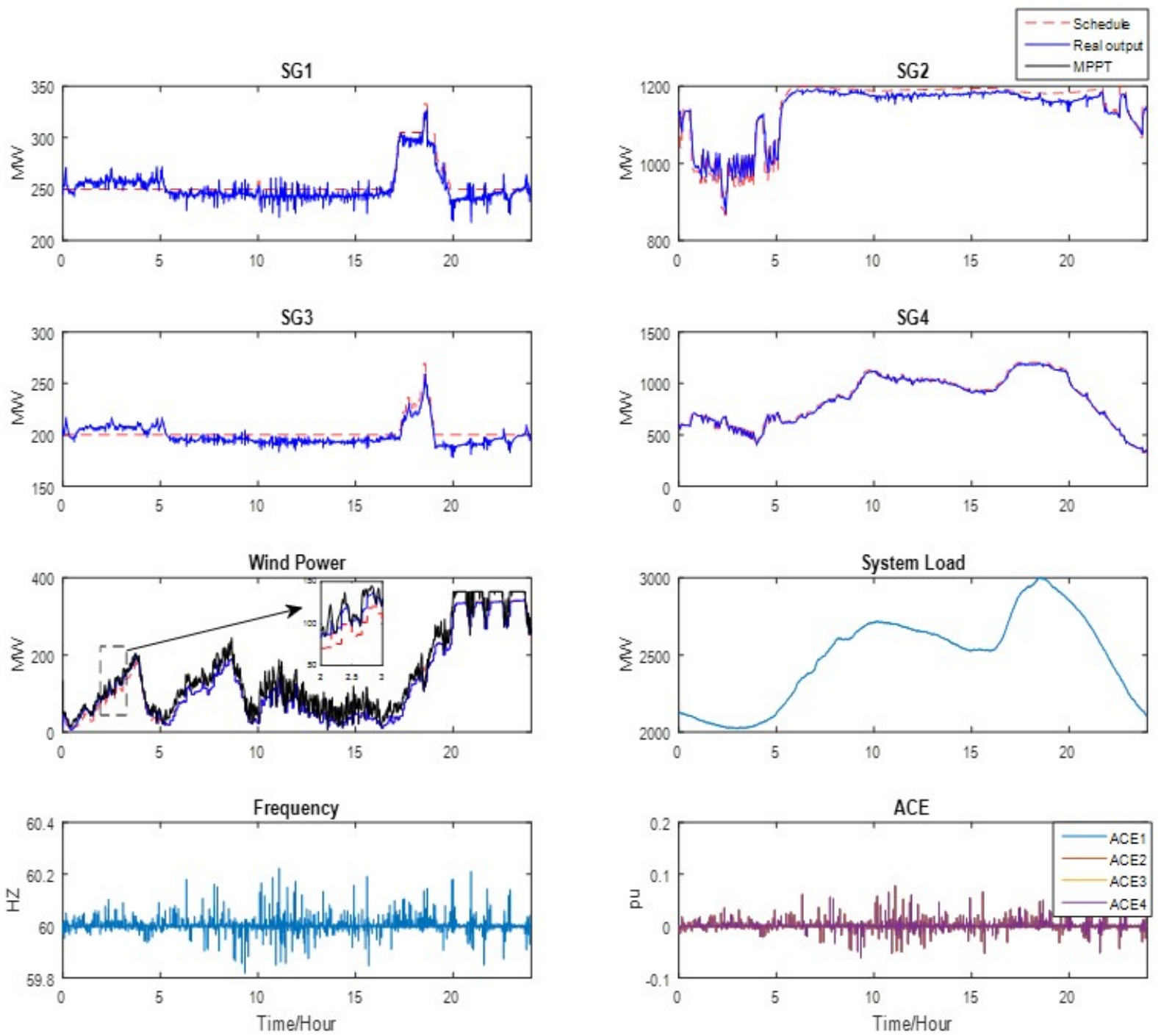

Figure 8. Scheduling (FESTIV) and real output (MAFRIT) of the wind turbine generators for 24 hours and the display of system load, frequency, and ACE

In the above secnario, wind penetration as calculated by energy during the 24-hour period is $6 \%$. To obtain a deeper understanding of the impact of system performance when wind is providing regulation, an $18 \%$ penetration scenario is simulated. Figure 9 presents the 24 -hour simulation results for that scenario, and Figure 10 presents the magnified 1-hour version. 

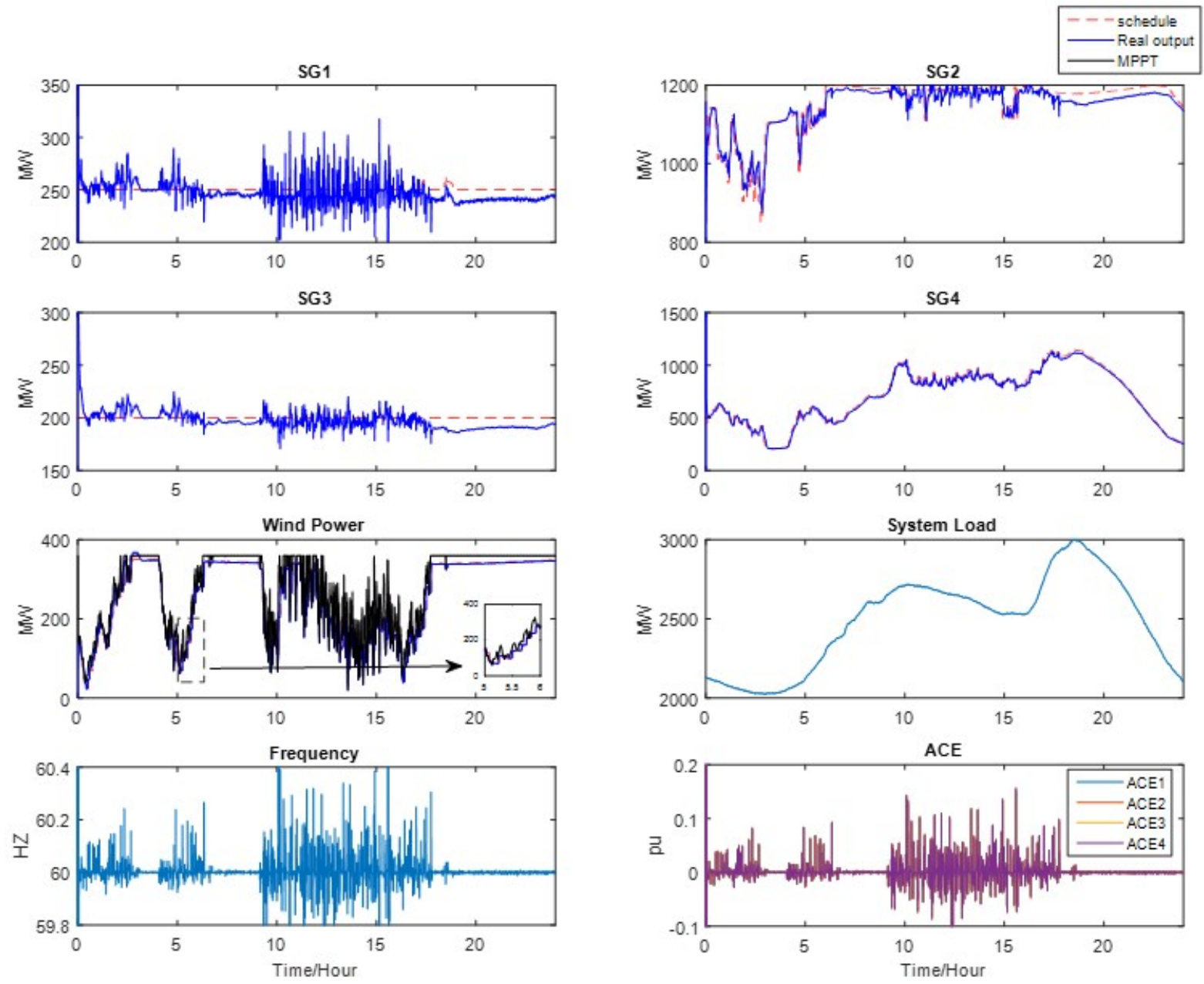

Figure 9. Scheduling (FESTIV) and real output (MAFRIT) of the wind turbine generators for 24 hours and the display of system load, frequency, and ACE under $18 \%$ wind energy penetration
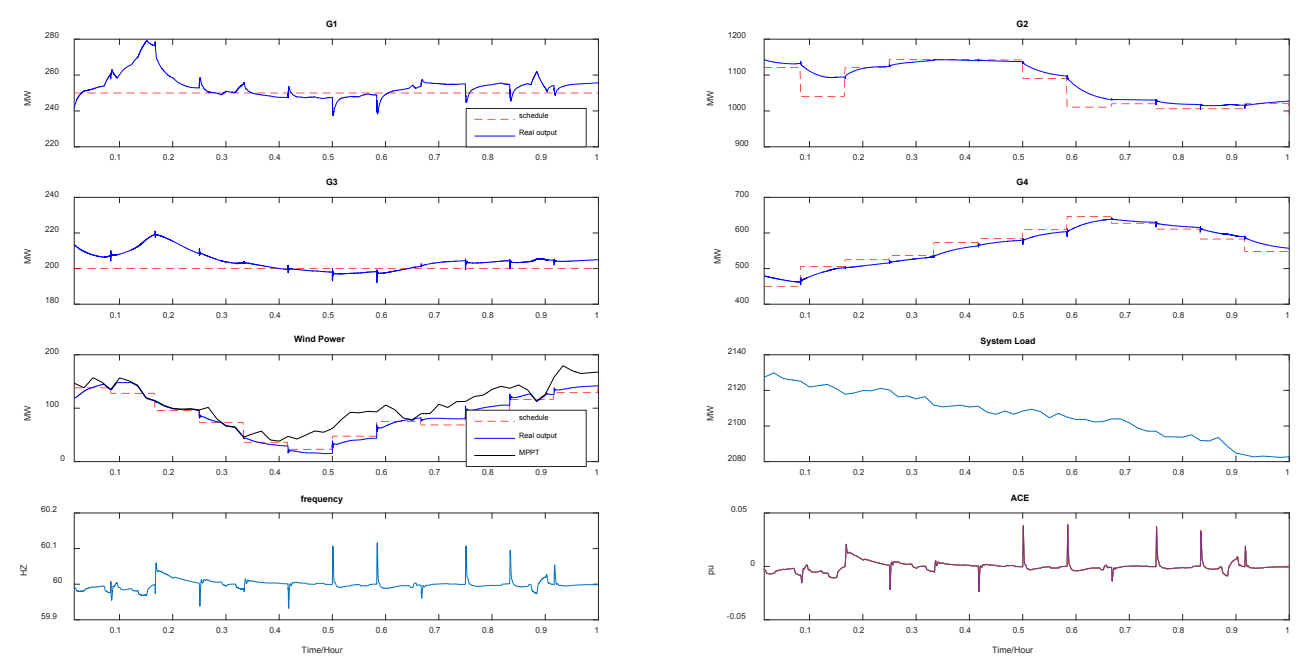

Figure 10. Scheduling (FESTIV) and real output (MAFRIT) of the wind turbine generators for 1 hour showing the system load, frequency, and ACE under $18 \%$ wind energy penetration 
Comparing the $18 \%$ penetration case to the $6 \%$ penetration case, the frequency and ACE devation in higher wind peneration perform worse than in the lower wind penetration because wind power varibilbity in the prior case is more significant than it is in the low penetration case. Note that in the high penetration case, when the wind power is capped by the maximum capacity of the wind power plant, the frequency is reduced. This means that the fast-change wind power will fulfill the challenge of frequency control for the grid. In the future high wind penetration case, more frequency responsive reserve is needed. 


\section{Results}

To study the interaction between primary and secondary reserves, we applied disturbances at different times during the 24-hour simulation. The primary focus is to assess the frequency response when wind is providing primary response, AGC, or both. Figure 11 illusrates that when wind is providing frequency regulation and an event happens, wind does not have enough headroom to provide a full-scale primary response. Wind that provides only primary response has a better frequency nadir. Wind that provides only AGC has a faster response to restore frequency.
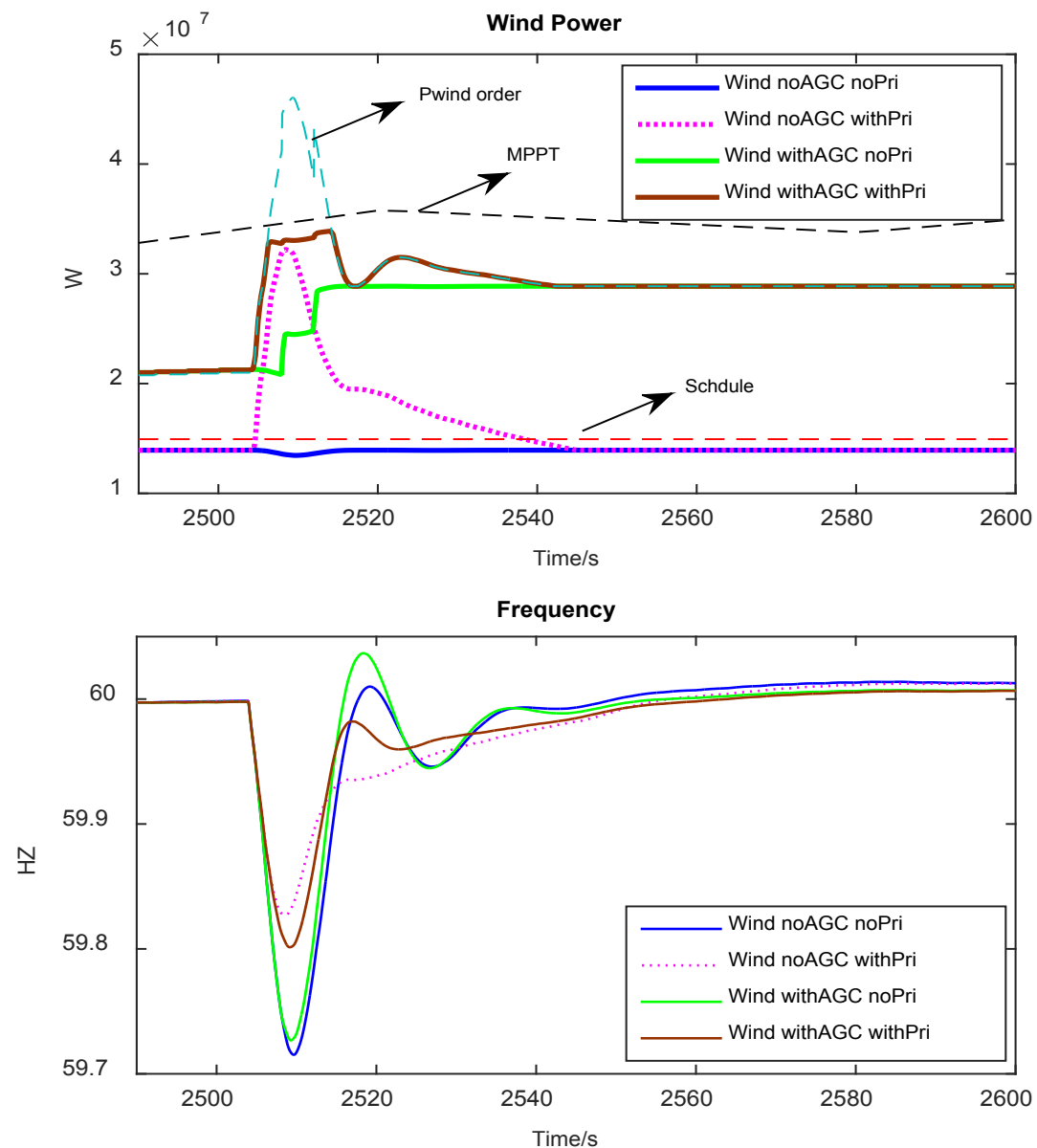

(a)

Figure 11. Wind power and system frequency when load increases by $50 \mathrm{MW}$ at $\mathrm{t}=2,504 \mathrm{~s}$ 

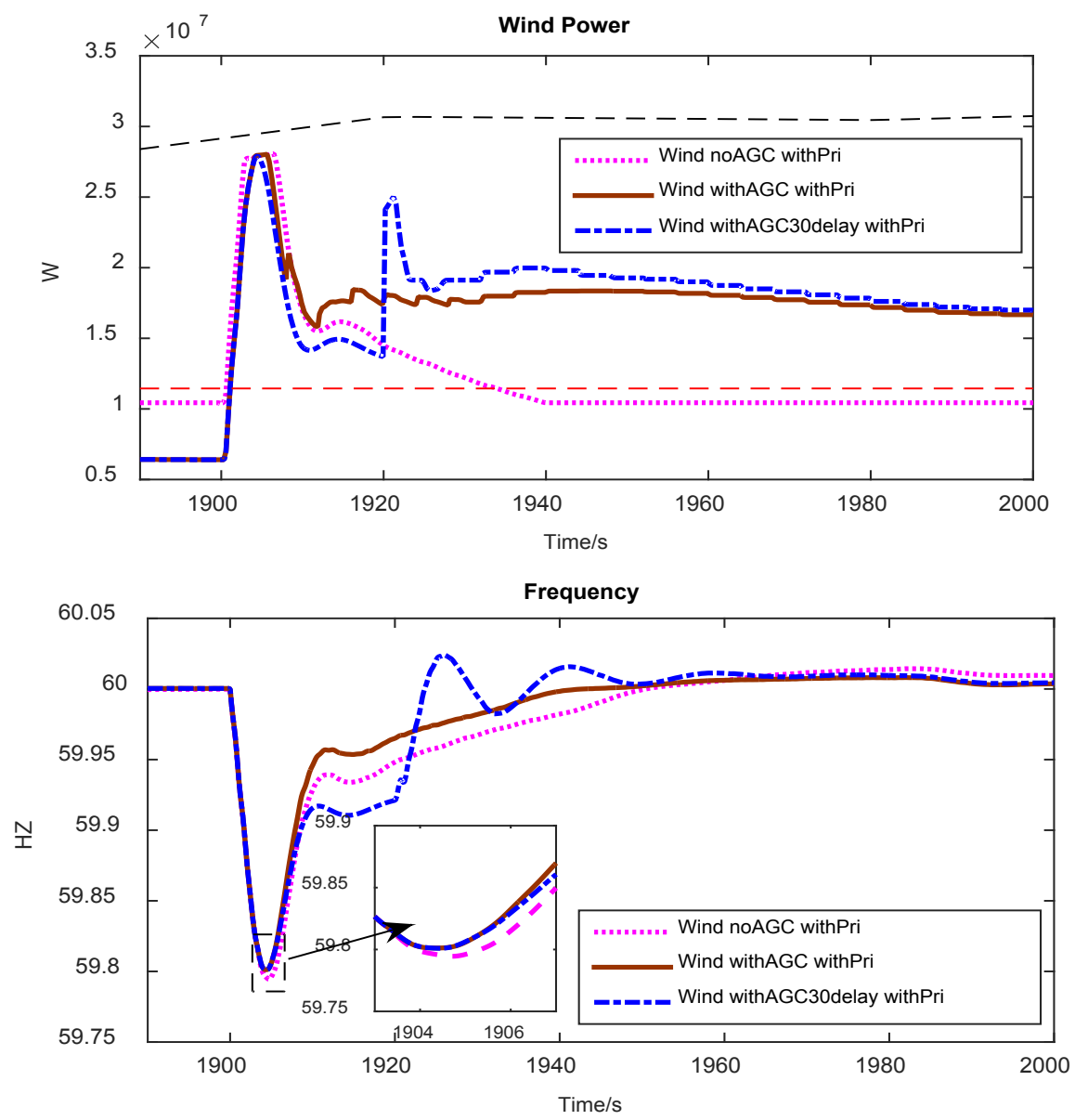

(b)

Figure 12. Wind power and system frequency when load increases by $50 \mathrm{MW}$ at $\mathrm{t}=1,900 \mathrm{~s}$

In most system operations, the AGC signal is disabled for tens of seconds immediately following a disturbance so that controllers can focus on restoring the system to equilibrium. We simulated that effect by disabling AGC for 30 seconds after the disturbance occured, as shown in Figure 12. Also, in this case, when the disturbance happens the wind power plant has enough energy to provide both primary and secondary response in full scale. The result shows that the the frequency nadirs for delayed and non-delayed AGC response are nearly the same. Comparing this to the no-AGC case, the wind with AGC will reduce the restoration time. In particular, in the case of the delayed AGC response, when the AGC kicks in 30 seconds after the event happpens, it brings the frequency back to the nominal value faster. 


\section{Conclusion}

The proposed tool allows for a better understanding of the interaction between PFR and secondary frequency response, which are responses typically simulated with separate tools. An improved understanding of the interactions of these controls is important so that any reliability issues that occur between the seams of these two time frames can be assessed. Careful consideration of these interactions will improve power system reliability and aid the design of control systems that will result in responses that are superior to those of conventional thermal generation and still have very little effect on the loading and life of the wind turbine and its components. A better understanding of the interaction between primary and secondary frequency control on multi-area systems with and without wind power plants providing both of these controls, and how they impact reliability compliance measures in various grids, will help the industry move forward on PFR market designs. 


\section{References}

1. ENTSO-E, UCTE, Operational Handbook Policy 1: Load-Frequency Control and Performance (Brussels, Belgium, March 2009).

2. Western Electricity Coordinating Council, "White Paper on Frequency Responsive Reserve Standard" (April 2005).

3. N. Miller et. al., "California ISO Frequency Response Study" (Final Draft), (Schenectady, NY: GE, November 2011).

4. J. Aho et. al., "Controlling Wind Turbines for Secondary Frequency Regulation: An Analysis of AGC Capabilities Under New Performance Based Compensation Policy," in the 13th International Workshop on Large-Scale Integration of Wind Power Into Power Systems as Well as on Transmission Networks for Offshore Wind Power Plants Proceedings (Berlin, Germany, November 2014).

5. J. H. Eto et. al., Use of Frequency Response Metrics to Assess the Planning and Operating Requirements for Reliable Integration of Variable Renewable Generation (Technical Report) (Berkeley, CA: Ernest Orlando Lawrence Berkeley National Laboratory, December 2010).

6. E. Ela et. al., Active Power Controls from Wind Power: Bridging the Gaps (Technical Report), NREL/TP-5D00-60574 (Golden, CO: January 2014).

7. L. Wang and D. Chen, "Automatic Generation Control (AGC) Dynamic Simulation in PSSE," Power Technology (February 2011). w3.usa.siemens.com.

8. L. Wang and D. Chen, "Experience with Automatic Generation Control (AGC) Dynamic Simulation in PSSE," Power Technology (August 2012). w3.usa.siemens.com.

9. “KERMIT Dynamic Models,” KERMIT Documentation for CA ISO Training.

10. KEMA, Inc., Research Evaluation of Wind Generation, Solar Generation, and Storage Impact on the California Grid (Project Report) (Sacramento, CA: California Energy Commission, June 2010).

11. KEMA, Inc., Emission II Study of Advanced Storage used for Frequency Regulation (Technical Report) (Albuquerque, NM: Sandia National Laboratories, December 2012).

12. KEMA, Inc., KERMIT Study Report: To Determine the Effectiveness of the AGC in Controlling Fast and Conventional Resources in the PJM Frequency Regulation Market (Technical Report) (Norristown, PA: PJM, December 2011).

13. E. Ela et. al, Active Power Control from Wind Power phase 1 Report (Technical Report) (Golden, CO: )

14. E. Ela et. al., "A Flexible Power System Operations Simulation Model for Assessing Wind Integration," in IEEE Power and Energy Society General Meeting Prcoeedings (Detroit, MI: July 2011). 


\section{Appendix: PSLF System Data}

1. System layout

The four-area system given in GE's PSLF is shown in Figure A-1. 


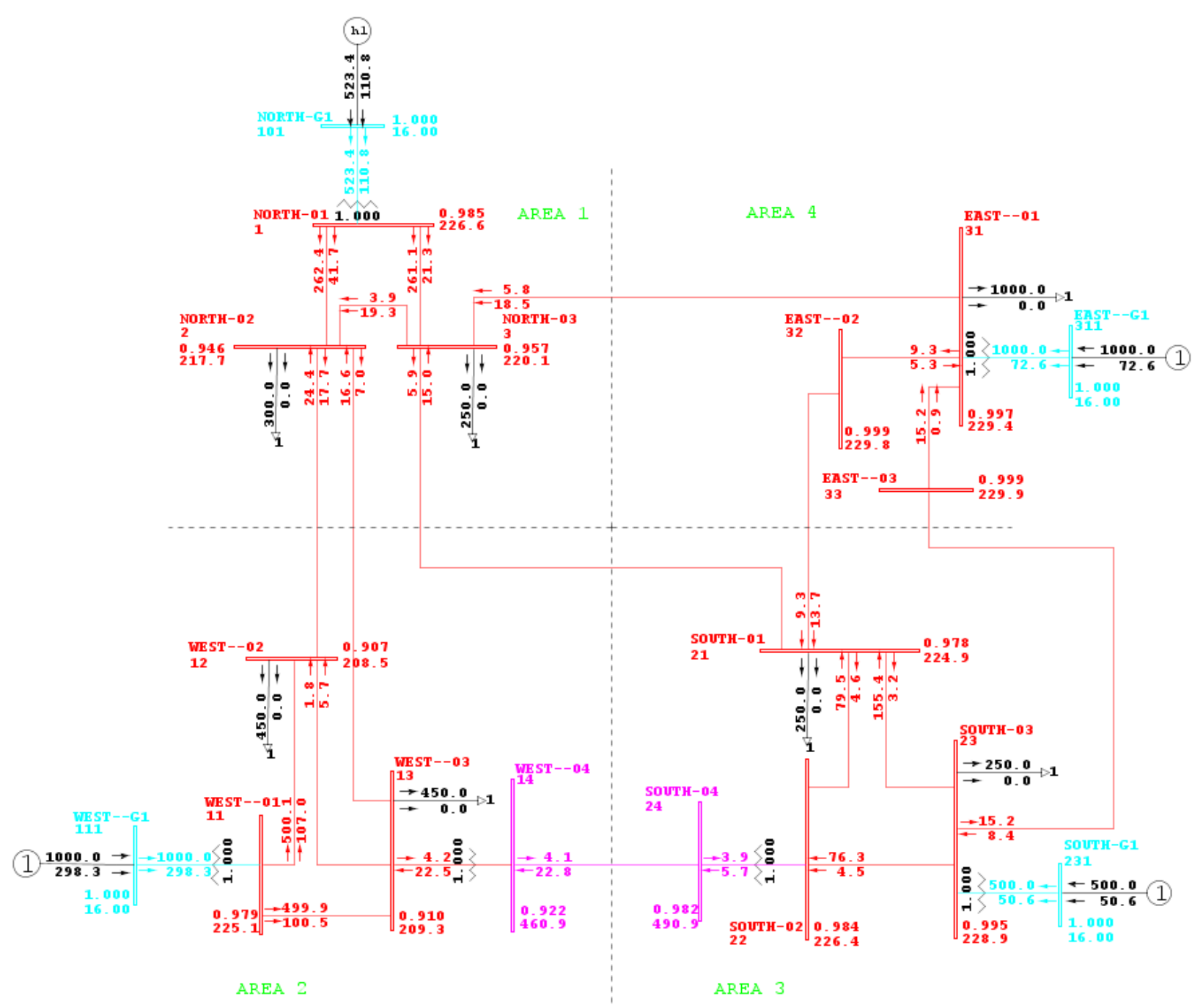

Figure A-1. Four-area system

The voltage levels for the buses shown in blue, red, and purple are $16 \mathrm{kV}, 230 \mathrm{kV}$, and $500 \mathrm{kV}$, respectively. Bus 101, Bus 1, and Bus 2 are used as examples to illustrate the meaning of the legends around the buses. 


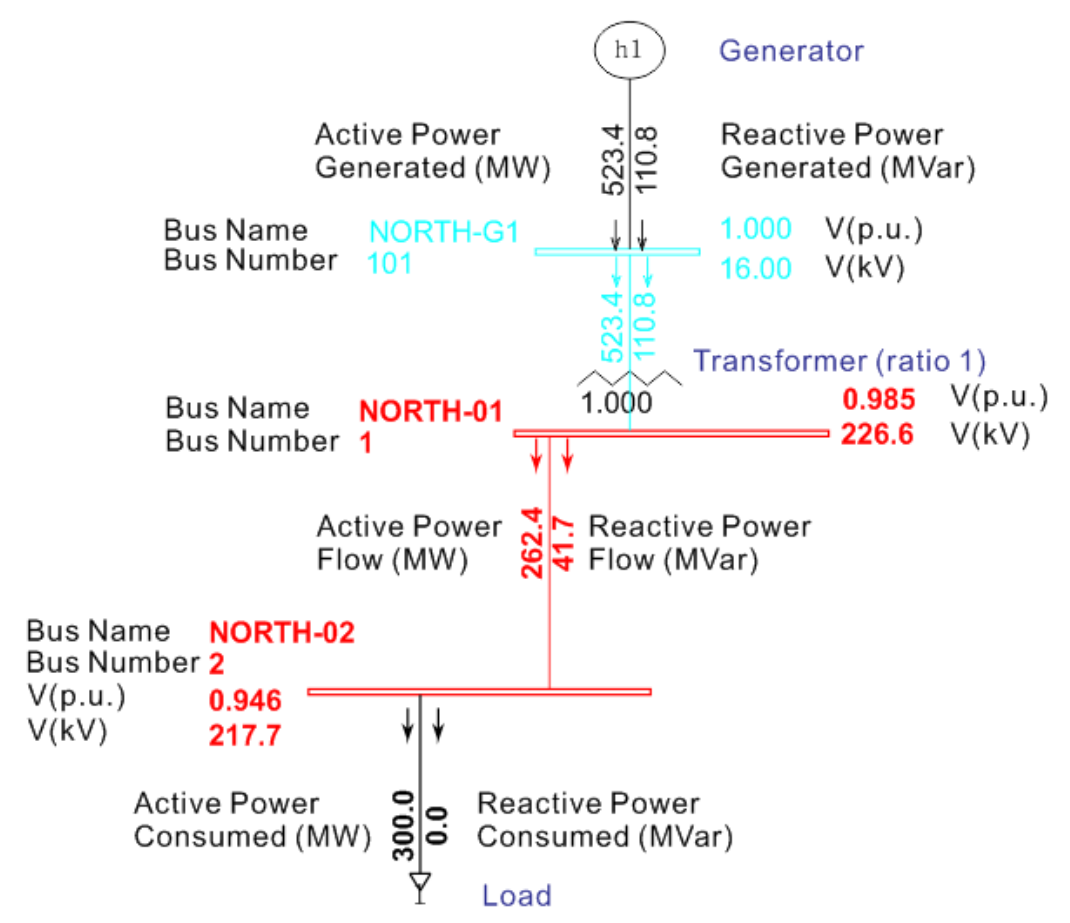

Figure A-2. Illustration of the legends

2. Summary of the system

Table A-1. Summary of the System

\begin{tabular}{c|c}
\hline \hline & Number \\
\hline \hline Areas & 4 \\
\hline Buses & 18 \\
\hline Lines & 18 \\
\hline Transformers & 6 \\
\hline Generators & 4 \\
\hline Loads & 7 \\
\hline
\end{tabular}


3. System power flow data

The power base for the system is 100 MVA.

A. Bus data

Table A-2. Bus Data

\begin{tabular}{|c|c|c|c|c|c|c|c|c|c|}
\hline Bus No. & Bus Name & $\begin{array}{c}\text { Voltage Base } \\
(\mathrm{kV})\end{array}$ & $\begin{array}{l}\text { Bus } \\
\text { Type }\end{array}$ & $\begin{array}{l}\text { VSched } \\
\text { (p.u.) }\end{array}$ & $\begin{array}{c}\mathrm{V} \\
\text { (p.u.) }\end{array}$ & $\begin{array}{c}\text { Angle } \\
\text { (deg) }\end{array}$ & $\begin{array}{l}\text { Vmax } \\
\text { (p.u.) }\end{array}$ & $\begin{array}{l}\text { Vmin } \\
\text { (p.u.) }\end{array}$ & Area \\
\hline 1 & NORTH-01 & 230 & 1 & 0.9897 & 0.9854 & -5.08 & 1.0397 & 0.9397 & 1 \\
\hline 2 & NORTH-02 & 230 & 1 & 0.9586 & 0.9464 & -12.91 & 1.0086 & 0.9086 & 1 \\
\hline 3 & NORTH-03 & 230 & 1 & 0.9675 & 0.957 & -12.9 & 1.0175 & 0.9175 & 1 \\
\hline 11 & WEST--01 & 230 & 1 & 0.9795 & 0.9787 & 6.30 & 1.0295 & 0.9295 & 2 \\
\hline 12 & WEST--02 & 230 & 1 & 0.9097 & 0.9065 & -9.35 & 0.9597 & 0.8597 & 2 \\
\hline 13 & WEST--03 & 230 & 1 & 0.9129 & 0.9099 & -9.32 & 0.9629 & 0.8629 & 2 \\
\hline 14 & WEST--04 & 500 & 1 & 0.9241 & 0.9218 & -9.62 & 0.9742 & 0.8741 & 2 \\
\hline 21 & SOUTH-01 & 230 & 1 & 0.9794 & 0.9776 & -13.75 & 1.0294 & 0.9294 & 3 \\
\hline 22 & SOUTH-02 & 230 & 1 & 0.9854 & 0.9843 & -11.35 & 1.0354 & 0.9354 & 3 \\
\hline 23 & SOUTH-03 & 230 & 1 & 0.9956 & 0.9951 & -9.15 & 1.0456 & 0.9456 & 3 \\
\hline 24 & SOUTH-04 & 500 & 1 & 0.983 & 0.9818 & -11.2 & 1.0330 & 0.9330 & 3 \\
\hline 31 & EAST--01 & 230 & 1 & 0.9977 & 0.9974 & -11.38 & 1.0476 & 0.9477 & 4 \\
\hline 32 & EAST--02 & 230 & 1 & 0.9996 & 0.9992 & -11.67 & 1.0496 & 0.9496 & 4 \\
\hline 33 & EAST--03 & 230 & 1 & 0.9998 & 0.9994 & -10.95 & 1.0498 & 0.9498 & 4 \\
\hline 101 & NORTH-G1 & 16 & 0 & 1.0000 & 1.0000 & 0 & 1.0500 & 0.9500 & 1 \\
\hline 111 & WEST--G1 & 16 & 2 & 1.0000 & 1.0000 & 11.19 & 1.0500 & 0.9500 & 2 \\
\hline 231 & SOUTH-G1 & 16 & 2 & 1.0000 & 1.0000 & -4.35 & 1.0500 & 0.9500 & 3 \\
\hline 311 & EAST--G1 & 16 & 2 & 1.0000 & 1.0000 & -6.58 & 1.0500 & 0.9500 & 4 \\
\hline
\end{tabular}

Bus no.: $\quad$ bus number

Bus name: bus name

Voltage base: the voltage base for the bus $(\mathrm{kV})$

Bus type: $\quad 0$ - slack bus (voltage magnitude and phase angle fixed

1 - load bus (PQ bus, unconstrained voltage phase angle and magnitude) 
2 - generator bus (PV bus, voltage control within generator limits)

VSched: scheduled voltage magnitude (p.u.)

actual voltage magnitude (p.u.)

actual voltage phase angle (degree)

voltage checking upper limit (p.u.)

voltage checking lower limit (p.u.)

Vmin:

area to which the bus belongs 
B. Line data

Table A-3. Line Data

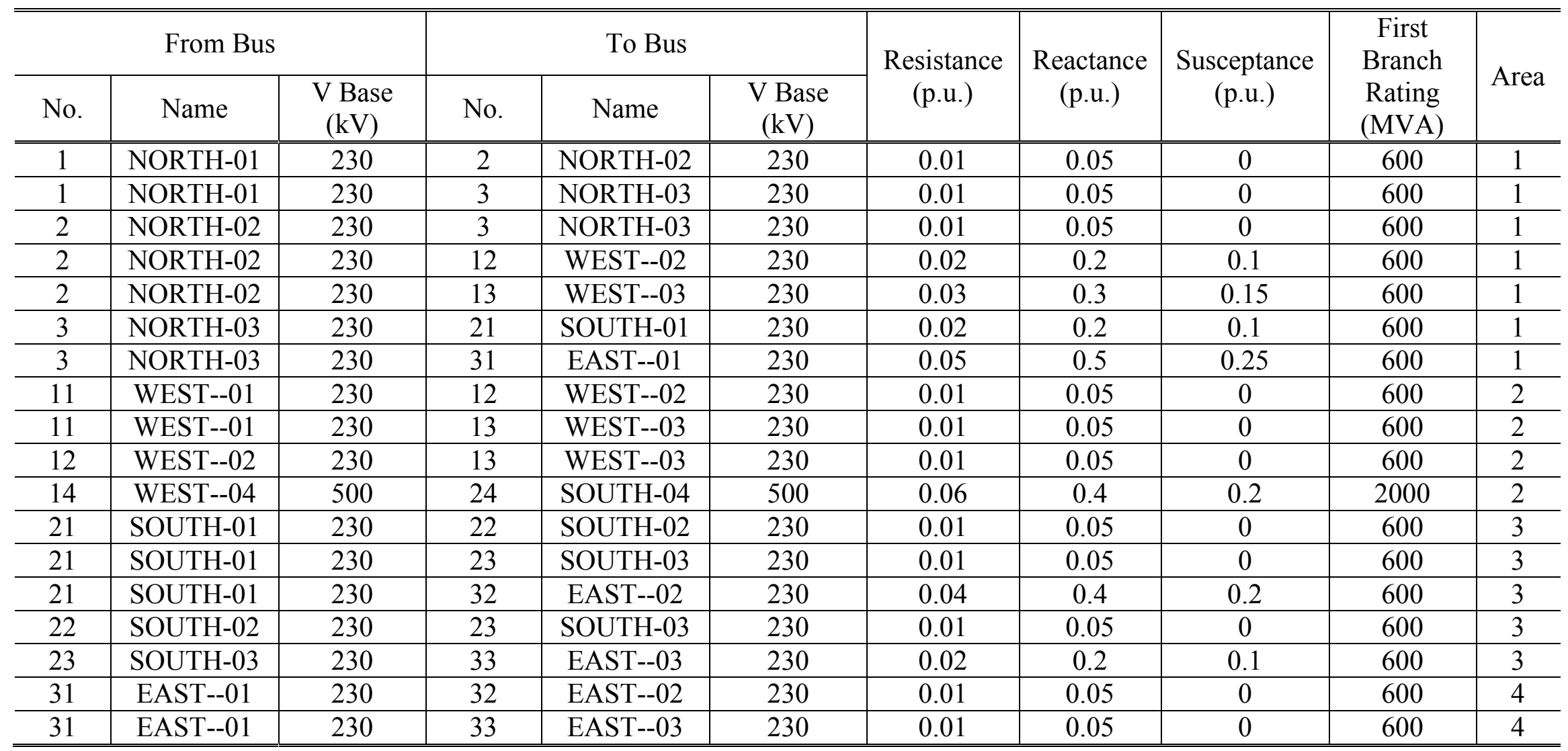

Resistance: branch section positive sequence resistance (p.u.)

Reactance: branch section positive sequence reactance (p.u.)

Susceptance: branch section positive sequence susceptance (p.u.) 
C. Transformer data

Table A-4. Transformer Data

\begin{tabular}{|c|c|c|c|c|c|c|c|c|c|c|c|c|c|c|}
\hline \multicolumn{3}{|c|}{ From Bus } & \multicolumn{3}{|c|}{ To Bus } & \multirow{2}{*}{$\begin{array}{c}\text { PowerB } \\
\text { ase } \\
\text { (MVA) }\end{array}$} & \multirow{2}{*}{$\begin{array}{c}\text { Primary } \\
\text { Winding } \\
\text { Nominal } \\
\mathrm{V}(\mathrm{kV})\end{array}$} & \multirow{2}{*}{$\begin{array}{c}\text { Secondary } \\
\text { Winding } \\
\text { Nominal } \\
\mathrm{V}(\mathrm{kV})\end{array}$} & \multirow[b]{2}{*}{$\begin{array}{c}\text { Tap } \\
\text { Ratio }\end{array}$} & \multirow[b]{2}{*}{$\begin{array}{c}\mathrm{R} \\
\text { (p.u.) }\end{array}$} & \multirow[b]{2}{*}{$\begin{array}{c}\text { X } \\
\text { (p.u.) }\end{array}$} & \multirow[b]{2}{*}{$\begin{array}{c}\text { B } \\
\text { (p.u.) }\end{array}$} & \multirow{2}{*}{$\begin{array}{c}\text { First } \\
\text { Branch } \\
\text { Rating } \\
\text { (MVA) }\end{array}$} & \multirow[b]{2}{*}{ Area } \\
\hline No. & Name & $\begin{array}{c}\mathrm{V} \\
\text { Base } \\
(\mathrm{kV}) \\
\end{array}$ & No. & Name & $\begin{array}{c}\mathrm{V} \\
\text { Base } \\
(\mathrm{kV}) \\
\end{array}$ & & & & & & & & & \\
\hline & $\begin{array}{c}\text { NORTH- } \\
01\end{array}$ & 230 & 101 & $\begin{array}{l}\text { NORTH- } \\
\text { G1 }\end{array}$ & 16 & 600 & 230 & 16 & 1 & 0 & 0.1 & 0 & 600 & 1 \\
\hline 11 & $\begin{array}{c}\text { WEST- } \\
01\end{array}$ & 230 & 111 & $\begin{array}{c}\text { WEST- } \\
\text { G1 }\end{array}$ & 16 & 1200 & 230 & 16 & 1 & 0 & 0.1 & 0 & 1200 & 2 \\
\hline 13 & $\begin{array}{c}\text { WEST- } \\
03\end{array}$ & 230 & 14 & $\begin{array}{c}\text { WEST- } \\
04\end{array}$ & 500 & 100 & 230 & 500 & 1 & 0.01 & 0.05 & 0 & 100 & 2 \\
\hline 22 & $\begin{array}{c}\text { SOUTH- } \\
02\end{array}$ & 230 & 24 & $\begin{array}{c}\text { SOUTH- } \\
04\end{array}$ & 500 & 100 & 230 & 500 & 1 & 0.01 & 0.05 & 0 & 100 & 3 \\
\hline 23 & $\begin{array}{c}\text { SOUTH- } \\
03 \\
\end{array}$ & 230 & 231 & $\begin{array}{c}\text { SOUTH- } \\
\text { G1 }\end{array}$ & 16 & 600 & 230 & 16 & 1 & 0 & 0.1 & 0 & 600 & 3 \\
\hline 31 & $\begin{array}{c}\text { EAST- } \\
01 \\
\end{array}$ & 230 & 311 & $\begin{array}{c}\text { EAST- } \\
\text { G1 }\end{array}$ & 16 & 1200 & 230 & 16 & 1 & 0 & 0.1 & 0 & 1200 & 4 \\
\hline
\end{tabular}

Power base: transformer power base (MVA)

R: $\quad$ resistance primary to secondary (p.u. value on transformer bases)

X: $\quad$ reactance primary to secondary (p.u. value on transformer bases)

B: $\quad$ Magnetizing susceptance (p.u. value on transformer bases) 
D. Generator data

Table A-5. Generator Data

\begin{tabular}{|c|c|c|c|c|c|c|c|c|c|c|c|c|c|}
\hline \multicolumn{3}{|c|}{ Bus } & \multirow[b]{2}{*}{$\begin{array}{l}\text { Control } \\
\text { Mode }\end{array}$} & \multirow[b]{2}{*}{$\begin{array}{l}\text { PGen } \\
(\mathrm{MW})\end{array}$} & \multirow[b]{2}{*}{$\begin{array}{l}\text { QGen } \\
\text { (MVar) }\end{array}$} & \multirow[b]{2}{*}{$\begin{array}{c}\text { Qmax } \\
\text { (MVar) }\end{array}$} & \multirow[b]{2}{*}{$\begin{array}{l}\text { Qmin } \\
\text { (MVar) }\end{array}$} & \multicolumn{3}{|c|}{ Regulating Bus } & \multirow[b]{2}{*}{$\begin{array}{c}\text { VSched } \\
\text { (p.u.) }\end{array}$} & \multirow[b]{2}{*}{$\begin{array}{c}\text { V } \\
\text { (p.u.) }\end{array}$} & \multirow[b]{2}{*}{ Area } \\
\hline No. & Name & $\begin{array}{c}\mathrm{V} \\
\text { Base } \\
(\mathrm{kV}) \\
\end{array}$ & & & & & & No. & Name & $\begin{array}{c}\mathrm{V} \\
\text { Base } \\
(\mathrm{kV})\end{array}$ & & & \\
\hline 101 & $\begin{array}{c}\text { NORTH- } \\
\text { G1 }\end{array}$ & 16 & 0 & 523.4 & 110.8 & 999 & -999 & 101 & $\begin{array}{c}\text { NORTH- } \\
\text { G1 }\end{array}$ & 16 & 1 & 1 & 1 \\
\hline 111 & $\begin{array}{c}\text { WEST-- } \\
\text { G1 }\end{array}$ & 16 & 0 & 1000 & 298.3 & 500 & -500 & 111 & $\begin{array}{c}\text { WEST-- } \\
\text { G1 }\end{array}$ & 16 & 1 & 1 & 2 \\
\hline 231 & $\begin{array}{c}\text { SOUTH- } \\
\text { G1 }\end{array}$ & 16 & 0 & 500 & 50.6 & 250 & -250 & 231 & $\begin{array}{c}\text { SOUTH- } \\
\text { G1 }\end{array}$ & 16 & 1 & 1 & 3 \\
\hline 311 & $\begin{array}{c}\text { EAST-- } \\
\text { G1 }\end{array}$ & 16 & 0 & 1000 & 72.6 & 500 & -500 & 311 & $\begin{array}{c}\text { EAST-- } \\
\text { G1 }\end{array}$ & 16 & 1 & 1 & 4 \\
\hline
\end{tabular}

Control mode:

PGen:

QGen:

Qmax:

Qmin:

Regulating bus:

VSched:

$\mathrm{V}$ :
0 - voltage at the regulated bus is held constant within Q limits of generators specified by Qmax and Qmin actual active power output of the generator (MW) actual reactive power output of the generator (MVar) maximum reactive power output of the generator (MVar) minimum reactive power output of the generator (MVar) the bus at which the voltage is regulated by the generator generator scheduled voltage magnitude (p.u.) generator actual voltage magnitude (p.u.) 
Table A-6. Load Data

\begin{tabular}{|c|c|c|c|c|c|c|c|c|c|c|}
\hline \multicolumn{3}{|c|}{ Bus } & \multicolumn{2}{|c|}{ Constant Power Load } & \multicolumn{2}{|c|}{$\begin{array}{c}\text { Constant Current } \\
\text { Load }\end{array}$} & \multicolumn{2}{|c|}{$\begin{array}{l}\text { Constant Admittance } \\
\text { Load }\end{array}$} & \multirow{2}{*}{$\begin{array}{l}\text { Load } \\
\text { Type }\end{array}$} & \multirow{2}{*}{ Area } \\
\hline No. & Name & $\begin{array}{c}\text { V Base } \\
(\mathrm{kV})\end{array}$ & $\begin{array}{l}\text { PLoad } \\
(\mathrm{MW})\end{array}$ & $\begin{array}{l}\text { QLoad } \\
\text { (MVar) }\end{array}$ & $\begin{array}{l}\text { IPLod } \\
\text { (MW) }\end{array}$ & $\begin{array}{l}\text { IQLod } \\
\text { (MVar) }\end{array}$ & $\begin{array}{l}\text { GLoad } \\
(\mathrm{MW})\end{array}$ & $\begin{array}{l}\text { BLoad } \\
\text { (MVar) }\end{array}$ & & \\
\hline 2 & NORTH-02 & 230 & 0 & 0 & 0 & 0 & 334.93 & 0 & 0 & 1 \\
\hline 3 & NORTH-03 & 230 & 0 & 0 & 0 & 0 & 272.96 & 0 & 0 & 1 \\
\hline 12 & WEST--02 & 230 & 0 & 0 & 0 & 0 & 547.56 & 0 & 0 & 2 \\
\hline 13 & WEST--03 & 230 & 0 & 0 & 0 & 0 & 543.53 & 0 & 0 & 2 \\
\hline 21 & SOUTH-01 & 230 & 0 & 0 & 0 & 0 & 261.58 & 0 & 0 & 3 \\
\hline 23 & SOUTH-03 & 230 & 0 & 0 & 0 & 0 & 252.49 & 0 & 0 & 3 \\
\hline 31 & EAST--01 & 230 & 0 & 0 & 0 & 0 & 1005.15 & 0 & 0 & 4 \\
\hline
\end{tabular}

Each load has three components: a constant power component, a constant current component, and a constant admittance component.

PLoad: $\quad$ active power consumed by the constant power component (MW)

QLoad: $\quad$ reactive power consumed by the constant power component (MVar)

IPLod: $\quad$ active power consumed by the constant current component at 1 p.u. voltage (MW)

IQLod: $\quad$ reactive power consumed by the constant current component at 1 p.u. voltage (MVar)

GLoad: $\quad$ active power consumed by the constant admittance component at 1 p.u. voltage (MW)

BLoad: $\quad$ reactive power consumed by the constant admittance component at 1 p.u. voltage (MVar)

Load type: $\quad 1$ - non-conforming (fixed)

0 - conforming (scalable) 
4. System dynamic data

A. Synchronous generator model and parameter

Table A-7. Synchronous Generator Model and Parameter

\begin{tabular}{|c|c|c|c|c|c|c|c|c|c|c|c|c|c|c|}
\hline & $\begin{array}{c}\text { Capacity } \\
\text { (MW) }\end{array}$ & Туре & Tpdo & Tppdo & Tpqo & tppqo & $\mathrm{H}$ & $\mathrm{D}$ & $\mathrm{Ld}$ & $\mathrm{Lq}$ & Lpd & $\mathrm{Lpq}$ & Lppd & Lppq \\
\hline NORTH-G1 & 282 & GENCC & 6 & 0.05 & 1 & 0.05 & 3.5 & 0 & 1.5 & 1.4 & 0.32 & 0.5 & 0.2 & 0.2 \\
\hline EAST-G1 & 1200 & GENSAL & 6 & 0.05 & & 0.05 & 2.8 & 0 & 1.05 & 0.69 & 0.32 & & 0.2 & \\
\hline WEST-G1 & 1200 & GENSAL & 6 & 0.05 & & 0.05 & 2.8 & 0 & 1.05 & 0.69 & 0.32 & & 0.2 & \\
\hline
\end{tabular}

\begin{tabular}{c|c|c|c|c|c|c|c|c|c|c|c}
\hline \hline & Capacity(MW) & Type & ll & s1 & s12 & ra & rcomp & xcomp & accel & pf & qf \\
\hline \hline NORTH-G1 & 318 & GENCC & 0.12 & 0.03 & 0.29 & 0 & -0.05 & -0.01 & 0.4 & 0.53 & 0.5 \\
\hline NORTH-G1 & 282 & GENCC & 0.12 & 0.03 & 0.29 & 0 & -0.05 & -0.01 & 0.4 & 0.53 & 0.5 \\
\hline SOUTH-G1 & 600 & GENSAL & 0.12 & 0.03 & 0.3 & 0.005 & 0.0 & 0.0 & & & \\
\hline EAST-G1 & 1200 & GENSAL & 0.12 & 0.03 & 0.3 & 0.005 & 0.0 & 0.0 & & & \\
\hline WEST-G1 & 1200 & GENSAL & 0.12 & 0.03 & 0.3 & 0.005 & 0.0 & 0.0 & & & \\
\hline \hline
\end{tabular}

GENSAL: Salient pole generator represented by equal mutual inductance rotor modeling GENCC: Generator represented by uniform inductance ratios rotor modeling to match WSCC type F model; shaft speed effects are neglected. Intended to model cross-compound machines represented as one generator in the load flow. 
B. Exciter model and parameter

Table A-8. Exciter Model and Parameter

\begin{tabular}{c|c|c|c|c|c|c|c|c|c|c|c}
\hline \hline & Capacity & & tr & tb & tc & ka & ta & vrmax & vrmin & ke & te \\
\hline \hline NORTH-G1 & 318 & Exdc1 & 0.0 & 0.0 & 0.0 & 40.00 & 0.10 & 0.0 & 0.0 & 0.0 & 0.50 \\
\hline NORTH-G1 & 282 & Exdc1 & tr & tb & tc & ka & ta & vamax & vamin & te \\
\hline SOUTH-G1 & 600 & Exac1 & 0.05 & 1.00 & 1.00 & 40.0 & 0.10 & 5.00 & -5.00 & \\
\hline EAST-G1 & 1200 & Exac1 & 0.05 & 1.00 & 1.00 & 40.0 & 0.10 & 5.00 & -5.00 & 0.5 \\
\hline WEST-G1 & 1200 & Exac1 & 0.05 & 1.00 & 1.00 & 40.0 & 0.10 & 5.00 & -5.00 & 0.5 \\
\hline \hline
\end{tabular}

\begin{tabular}{c|l|c|c|c|c|c|c|c|c|c}
\hline \hline & & $\mathrm{kf}$ & $\mathrm{Tf1}$ & $\mathrm{Tf} 2$ & & & $\mathrm{E} 1$ & $\mathrm{Se} 1$ & $\mathrm{E} 2$ & $\mathrm{Se} 2$ \\
\hline \hline NORTH-G1 & Exdc1 & 0.05 & 1.0 & 0 & & & 2.2 & 0.1 & 3.5 & 0.4 \\
\hline NORTH-G1 & Exdc1 & $\mathrm{kf}$ & $\mathrm{Tf}$ & $\mathrm{kc}$ & $\mathrm{kd}$ & $\mathrm{ke}$ & $\mathrm{E} 1$ & $\mathrm{Se} 1$ & $\mathrm{E} 2$ & $\mathrm{Se} 2$ \\
\hline SOUTH-G1 & Exac1 & 0.2 & 1.0 & 0.1 & 0.6 & 1.0 & 1.0 & 0.03 & 2.0 & 0.3 \\
\hline EAST-G1 & Exac1 & 0.2 & 1.0 & 0.1 & 0.6 & 1.0 & 1.0 & 0.03 & 2.0 & 0.3 \\
\hline WEST-G1 & Exac1 & 0.2 & 1.0 & 0.1 & 0.6 & 1.0 & 1.0 & 0.03 & 2.0 & 0.3 \\
\hline \hline
\end{tabular}

Exdc1: IEEE (1980) DC1 excitation system model with added speed multiplier

Exac1: IEEE type AC1 excitation system with added speed multiplier and with VR limits modified to agree with IEEE type AC1A. 
C. Governor model and parameter

Table A-9. Governor Model and Parameter

\begin{tabular}{|c|c|c|c|c|c|c|c|c|c|c|c|c|}
\hline & Capacity & Type & $\mathrm{k}$ & T1 & $\mathrm{T} 2$ & T3 & uo & $\mathrm{uc}$ & pmax & pmin & $\mathrm{T} 4$ & K1 \\
\hline \multirow{5}{*}{ NORTH-G1 } & \multirow{5}{*}{$318+282$} & \multirow{5}{*}{ IEEEG1 } & 20.0000 & 0.5 & 0.0 & 0.2 & 0.06 & -0.5 & 1 & 0.0 & 0.4 & 0.3 \\
\hline & & & 0.0 & 0.0 & 0.0 & 0.0 & 0.0 & 0.0 & 0.0 & 0.0 & 0.0 & 0.0 \\
\hline & & & 0.0 & 7.5 & 0.23 & 0.0 & 0.6 & 0.0 & 0.47 & 0.0 & 0.0 & \\
\hline & & & Gv4 & Pgv4 & Gv5 & Pgv5 & Gv6 & Pgv6 & & & & \\
\hline & & & 0.0 & 0.0 & 0.0 & 0.0 & 0.0 & 0.0 & & & & \\
\hline
\end{tabular}

\begin{tabular}{|c|c|c|c|c|c|c|c|c|c|c|c|c|}
\hline & Capacity & Type & rperm & rtemp & $\operatorname{tr}$ & $\mathrm{tf}$ & $\operatorname{tg}$ & velm & $\operatorname{gmax}$ & gmin & tw & at \\
\hline \multirow{7}{*}{$\begin{array}{c}\text { SOUTH-G1 } \\
\text { EAST-G1 } \\
\text { WEST-G1 }\end{array}$} & \multirow{7}{*}{$\begin{array}{c}600 \\
1200 \\
1200\end{array}$} & \multirow{7}{*}{ HYGOV } & 0.05 & 0.5 & 10 & 0.05 & 0.5 & 0.2 & 1 & 0 & 2.5 & 1.25 \\
\hline & & & Pgv0 & gv1 & pgv1 & gv2 & pgv2 & gv3 & pgv3 & gv4 & pgv4 & gv5 \\
\hline & & & 0 & 0 & 0 & 0 & 0 & 0 & 0 & 0 & 0 & 0 \\
\hline & & & tblade & dturb & qnl & ttrip & tn & $\operatorname{tnp}$ & $\mathrm{db} 1$ & eps & $\mathrm{db} 2$ & gv0 \\
\hline & & & 99 & 0.5 & 0.08 & 0 & 0 & 0 & 0 & 0 & 0 & 0 \\
\hline & & & & pgv5 & hdam & bgv0 & bgv1 & bgv2 & bgv3 & bgv4 & bgv5 & bmax \\
\hline & & & & 0 & 1 & 0 & 0 & 0 & 0 & 0 & 0 & 0 \\
\hline
\end{tabular}

IEEEG1: IEEE steam turbine/governor model (with deadband and nonlinear valve gain added)

HYGOV: Hydro turbine and governor. Represents plants with straight-forward penstock configurations and electro-hydraulic governors that mimic the permanent/temporary droop characteristics of traditional dashpot-type hydraulic governors. 


\section{Wind power plant data}

There are two kinds of wind power plant models in MAFRIT: a DFIG power plant with phasor dynamic model and the simplified wind power plant model using controlled current source and algebraic expression to present the relationship between the nominal wind speed and power.

\section{i. Phasor dynamic model of DFIG}

The DFIG parameters are grouped in four categories: Generator data, Converters data, Turbine data, and Control parameter.

1. Generator data

\section{Table A-10. Generator Data of DFIG}

\begin{tabular}{c|c|c|c|c|c|c|c|c|c|c}
\hline \hline Pn (W) & Vn (V) & Fn (Hz) & Rs (p.u.) & Lls (p.u.) & Rr'(p.u.) & Llr'(p.u.) & Lm (p.u.) & H (s) & F (p.u.) & p \\
\hline \hline $90 * 1.5 \mathrm{e} 6$ & 575 & 60 & 0.00706 & 0.171 & 0.005 & 0.156 & 2.9 & 5.04 & 0.0 .1 & 3 \\
\hline \hline
\end{tabular}

[Pn Vn Fn]: [Nominal power, line-to-line voltage, frequency]

[Rs Lls]: [Stator resistance, stator inductance]

[Rr' Llr' Lm]: [Rotor resistance, rotor inductance, magnetizing inductance]

$[\mathrm{H}, \mathrm{Fm}, \mathrm{p}]: \quad$ [Inertia constant, friction factor, pairs of poles]

\section{Turbine data}

Table A-11. Turbine Data of DFIG

\begin{tabular}{c|c|c|c|c|c|c|c|c|c}
\hline \hline Pm (W) & w_a (p.u.) & w_b (p.u.) & w_c (p.u.) & w_d (p.u.) & Pm_c & Vw_c & Kp & $\beta m a x$ & $(d \beta / d t)$ max \\
\hline \hline $90^{*} 1.5 \mathrm{e} 6$ & 0.7 & 0.71 & 1.2 & 1.21 & 0.73 & 12 & 500 & 45 & 2 \\
\hline \hline
\end{tabular}




\section{Converter data}

Table A-12. Converter Data of DFIG

\begin{tabular}{c|c|c|c|c|c|c}
\hline \hline $\begin{array}{c}\text { Converter maximum P } \\
\text { (p.u.) }\end{array}$ & L (p.u.) & R (p.u.) & IL (p.u.) & Ph_IL (deg) & Vdc (V) & Cdc (F) \\
\hline 0.5 & 0.15 & $0.15 / 100$ & 0 & 90 & 1200 & $90 * 0.1$ \\
\hline \hline
\end{tabular}

4. Control data

Table A-13. Control Data of DFIG

\begin{tabular}{|c|c|c|c|c|c|c|c|c|c|c|c|c|c|c|c|c|}
\hline Mode & $\mathrm{V}_{\text {ref }}$ & Iq_ref & Kp1 & Ki1 & Xs & $\mathrm{Kp} 2$ & $\mathrm{Ki} 2$ & Kp3 & Ki3 & $\mathrm{Kp} 4$ & $\mathrm{Ki} 4$ & Kp5 & Ki5 & $\begin{array}{c}\mathrm{dV} / \\
\mathrm{dt}) \\
\max \\
\end{array}$ & $\begin{array}{c}\mathrm{dP} / \mathrm{d} \\
\mathrm{t}) \\
\max \\
\end{array}$ & $\begin{array}{c}\mathrm{dI} / \mathrm{d} \\
\mathrm{t}) \\
\max \\
\end{array}$ \\
\hline $\begin{array}{c}\text { Voltage } \\
\text { regulatio } \\
n\end{array}$ & 1.0 & 0 & 1.25 & $\begin{array}{c}300 / \\
100\end{array}$ & 0 & 1 & $\begin{array}{l}100 / \\
200\end{array}$ & $\begin{array}{c}0.00 \\
2\end{array}$ & 0.05 & 1 & 100 & 0.3 & 8 & 100 & 1 & 200 \\
\hline
\end{tabular}

Mode: Voltage regulation/VAR regulation

[Kp1 Ki1]: Voltage regulation mode/grid voltage regulator gains

[Kp1 Ki1]: VAR regulation mode/reactive power regulator gains

[Kp2 Ki2]: Power regulator gains

[Kp3 Ki3]: $\quad$ DC bus voltage regulator gains

[Kp4 Ki4]: Grid-side converter current regulator gains

[Kp5 Ki5]: Rotor-side converter current regulator gains

ii. Simplified wind power plant model

The simplified wind power plant model presented here generates power using a linear relationship between the nominal wind speed and nominal power. When the wind speed reaches the maximal value, the wind power plant trips from the grid. When the wind speed is between the nominal speed and the maximal value, the power is fixed to 1 p.u. 
Table A-14. Parameter of Simplified Wind Power Plant Model

\begin{tabular}{c|c|c}
\hline \hline Nominal Power(MW) & Nominal Wind Speed $(\mathrm{m} / \mathrm{s})$ & $\begin{array}{c}\text { Maximal Wind Speed } \\
(\mathrm{m} / \mathrm{s})\end{array}$ \\
\hline 360 & 13.5 & 15 \\
\hline \hline
\end{tabular}

